\title{
Das erloschene Slawentum des Obermaingebietes und sein vorchristlicher Opferbrauch (trebo) im Spiegel eines mutmaßlich würzburgischen Synodalbeschlusses aus dem 10. Jahrhundert
}

\author{
Hans-Dietrich Kahl
}

The Old Slavic term trěba (sacrifice) has hardly survived Christianization. Presumably the oldest report about this ritual dates from 785 and appears as the Würzburg Synodal Resolution from the $10^{\text {th }}$ century. The resolution speaks about the draconic measures against church heretics, all of whom were strangely of non-Frankish origin. Slavic and German imperial subjects are treated equally, and Slavs have their own judicial community. Their religion is syncretistic and the degree of their Christianization unclear. A strong resistance against the Church was evident. Trebo (sic), the ritual feast, was one of the forbidden returns to "paganism." Analyzed are grammatical usages of the terms idolatria, idolothytum, and paganismus, and a new insight into the prehistory of the Bamberg diocese is given.

Übersicht: Ein altslawisches Opferwort in den Strudeln der Christianisierung (S. [11] - [14]). - 2. Eine Quelle im Irrgarten der Zuweisungsversuche (S. [14] - [23]). - 3. Kirche mit zweierlei Maß (S. [24] - [30]). - 4. Eigenes Recht im fränkischen Untertanenverband (S. [31] - [32]). - 5. Idolatria, idolothytum und paganismus im Übergangsfeld zwischen alter und neuer Religion (S. [33] - [40]). - 6. Neue Fragen (S. [40] - [41]).

\section{Ein altslawisches Opferwort in den Strudeln der Christianisierung}

Der gemeinslawische Wortstamm, von dem ein wichtiger Ableger hier ins Auge gefaßt werden soll, ist semantisch reich entfaltet und schwer zu durchschauen ${ }^{1}$. Die Grundbedeutung dürfte "reiben" gewesen sein, entwickelt einerseits zu »reinigen«, dann »roden«, ja »kastrieren«, andererseits - etwa über die Brücke von »bedrängen« - zu »unausweichlich sein«: Die Verbform trěba/treba/trzeba steht weit verbreitet für »es ist nötig; man muß«, mit altpreuß. enterpo »es nützt« als bemerkenswertem Gegenstück. Auch das Germanische steuert unmittelbar Verwandtes bei und beweist damit, daß die Wurzel weiter zurückreicht als die Trennung von satem- und centum-Sprachen: got. paúrfts beispielsweise (mit -aú- orthographisch für den Kurzlaut -o-), das »nötig« und "nützlich« vereint; deutsch schließen be-dürfen und Not-durft sich an, um es damit bewenden zu lassen.

1 F. MIKLOSICH, Etymologisches Wörterbuch der slavischen Sprachen, Wien $1886=$ Amsterdam 1970, S. 352 353, s.vv. ter- u. terbu- 1.2.; weiteres Anm. 2 u. 5. - Zur Ergänzung: S. FEIST, Vergleichendes Wörterbuch der gotischen Sprache, Leiden 1936/39, S. 491 f. s. vv. paúrban, paúrfts; J. de VRIES, Altnordisches etymologisches Wörterbuch, Leiden 1961, S. 627 s. v. purfa samt dort aufgeführten Verweisstichwörten. 
Verhältnismäßig alt sein muß auch das Substantiv, das die gleich vorzustellende mittellateinische Quelle trebo schreibt - man steht vor der Wahl, ob damit ein Irrtum von sprachunkundigen Außenseitern belegt ist, die den Akkusativ für den Nominativ nahmen, oder ob das für diese Gegend ein sonst ungebräuchliches Neutrum bezeugt. Im übrigen kommt das Wort nur als Femininum vor, trěba/treba/trzeba, gleichfalls gemeinsames Gut aller slawischen Sprachen, zumindest auf Zeit - wie weit die erkennbare Verbreitung durch kirchenslawischen Einfluß bedingt wurde, bleibt ein Problem für sich ${ }^{2}$. Bezeichnet worden sein muß damit ein Opferbrauch der alten, der vorchristlichen Religion ${ }^{3}$.

An welche Nuance der vorgeführten Palette knüpfte der Ausdruck an? Das ist schwer zu bestimmen. War im Ursprung »das unbedingt Notwendige (und damit Nutzbringende) « gemeint? Ebensogut könnte »Reinigung« zugrunde liegen, vielleicht auch, daraus entwickelt, "Sühne". Oder ist an ganz anderer Stelle anzusetzen, etwa beim Abhäuten und Ausweiden des Opfertieres - wichtigen Schritten zu vorbereitender »Reinigung« des Opfermahls - oder gar bei dem urtümlichen Reibevorgang, der einmal ein heiliges Feuer erzeugt haben mag? Dann hätte die Sprache sich pars pro toto mit Andeutung des Auftakts begnügt und das eigentliche sacrificium, das "heilige Werk" selbst, unbenannt in der Tabu-Zone belassen. Der Spielraum, den die Phantasie hier behält, zeigt sich unerwünscht weitläufig. Es fehlt uns an Wissen um die »liturgischen « Aspekte des sakralen Vorgangs, die allein diese Weitläufigkeit einengen könnten.

Festzuhalten ist, daß treba (trebo?) wohl auch in Personennamen einging, die ihrerseits dann auf Ortsnamenbildung wirkten. An das mainfränkische Trebgast (wohl ${ }^{*}$ Trěbogość, zu ${ }^{*}$ Trěbogost) wird unten nochmals zu erinnern sein ${ }^{4}$. Der sicher alte Name, und das ist bemerkenswert, vermochte den Glaubenswechsel zu überdauern. Das paßt zu einer merkwürdigen Bedeutungsentwicklung, die die erloschenen slawischen Mundarten an der Niederelbe aufweisen: Obwohl vorchristlichem Kultbrauch, also einem »Teufelswerk" gewidmet, vermochte dravänopolab. tribe/trewe zu Namen für »Weihnachten«, das »heilige Christfest«, zu werden ${ }^{5}$ - eine auffällige Parallelentwicklung zum nordgerm.

2 Für das Russische als Lehnwort aus dem Kirchenslawischen aufgefaßt von M. VASMER, Russisches etymologisches Wörterbuch III, Heidelberg 1958, S. 133 s.v. treba, vgl. S. 95 f. s.v. tereb; ein Beleg, der vor das Aksl. zurückreicht, ist, wie noch darzulegen, offenbar nicht bekannt. - Bedeutende Materialsammlungen: F. MIKLOSICH, Die christliche Terminologie der slavischen Sprachen, in: Denkschr. d. Akademie d. Wiss. Wien 24 (1876), S. 31 f., dazu S. 36 Nr. 6, vgl. S. 18, 22 u. 37; Slovník jazyka Staroslovénskeha (Českoslov. Akademie věd), fasc. 43, Praha 1990, S. 507-509 s.v. trěba (aufgeteilt auf zwei gleichlautende Lemmata). Vgl. A. BRÜCKNER, Slaven und Litauer, bei (P.D.) CHANTEPIE DE LA SAUSSAYE, Lehrbuch der Religionsgeschichte II, 4. Aufl., hg. von A. Bertholet - E. Lehmann, Tübingen 1925, S. 521; DERS., Słownik etymologiczny jęzika Polskiego, 2. Aufl. (1936) 1957, S. 579 f. s.vv. trzeba u. trzebić; W. ANTONIEWICZ, Ofiary, in: Słownik starożytności Słowiańskich (künftig: SSS) VI (1980), S. 461 f. (Lit.); L. MOSZYŃSKI, Die vorchristliche Religion der Slaven im Lichte der slavischen Sprachwissenschaft, Köln-Weimar-Wien 1992, S. 108 f.; A. GIEYSZTOR, Opfer und Kult in der slavischen Überlieferung; in: Frühmittelalterl. Studien 18 (1994), bes. S. 251 (Lit.).

3 MOSZYŃSKI, S. 121-123, vgl. 125, begründet, warum "vorchristlich « vor dem vielfach eingesetzten »heidnisch « vorzuziehen ist. Seine Argumente lassen sich ergänzen nach H.-D. KAHL, Die ersten Jahrhunderte des missionsgeschichtlichen Mittelalters, bei K. Schäferdiek (Hg.), Die Kirche des früheren Mittelalters I (Kirchengeschichte als Missionsgeschichte, hg. H. Frohnes u.a., Bd. II/1), München 1978, S. 26-28, 45-47, 50-53, 58 u.ö.

4 Unten bei Anm. 50.

${ }^{5}$ F. MIKLOSICH, Die slav. Monatsnamen, in: Denkschr. d. Akademie d. W. Wien 17 (1867), S. 22 Nr. 62 mit älterer Kontroverslit. zur Deutung; DERS. 1876, S. 22, Nr 4; J. WACHTLÓWNA, Poł. trébs, tribnv, in: Slavia Occidentalis 12 (1933), S. 299-301, vgl. 425 (mir freundlich zugänglich gemacht durch Frau Dr. B. WAVRA, Gießen); F. HINZE, Deutsches und Slawisches im Spiegel der dravänopolab. Monatsnamen, in: Zschr. f. Slawistik 19 (1974), S. 729, vgl. 730 u. 733; R. OLESCH, Die christl. Terminologie im Dravänopolabischen, in: Zschr. f. slav. Philologie 39 (1976), S. 21; DERS. Die Monatsnamen im Spätdravänischen, in: Kwartalnik Neophilo- 
jul, ohne daß sich eine Querverbindung wahrnehmen ließe ${ }^{6}$. Der »heidnische« Gehalt muß also hier dort so weit überlagerungsfähig gewesen sein, daß die Möglichkeit dieser Umdeutung offen blieb. Die Gemeinsamkeit geht so weit, daß die Weiterverwendung eines altüberkommenen Ausdrucks unter den drei Hochfesten des christlichen Kirchenjahres nur für dieses eine gilt, nicht auch für »Ostern« und »Pfingsten«: Für diese traten beide Male Entlehnungen aus kirchensprachlichem Vorbild ein, bei den Dravänopolaben aus der deutschsprachigen Terminologie des hier missionierenden Erzbistums Mainz (gôstráy/justrój usw. bzw. pangtgîste/panckjüst usw.) ${ }^{7}$, in Skandinavien aus kirchenlat. pascha und pentecoste. Bei der »Christianisierung« der mittelalterlichen Vorform von tribe/trewe wurde also offenbar nicht an einen allgemeineren Sinngehalt angeknüpft, etwa "religiöses Hochfest schlechthin", sondern an ein bestimmtes, spezifisches Fest, das sich von anderen abhob. Es muß wohl in etwa derselben Jahreszeit angesiedelt gewesen sein, sonst wäre der Übergang kaum verständlich, so, wie das für das nordische jul ausdrücklich bezeugt ist mitsamt einer Verlegung um wenige Wochen auf den christlichen Festtermin ${ }^{8}$. Für das Slawische allerdings fehlt uns jede ergänzende Auskunft ${ }^{9}$. Die Mainzer Kirchenprovinz reichte von der Niederelbe bis zum Obermain und in die Zentralalpen; sie schloß damit außer dem »Hannöverschen Wendland «, dem Kerngebiet der Dravänopolaben, noch weitere Teile der Slavia submersa Deutschlands ein. Ob auch sie an der Entwicklung von treba zu »Weihnachten« teil hatten, läßt sich mangels Aufzeichnungen nicht kontrollieren; für das Maingebiet ergeben sich Bedenken ${ }^{10}$.

In den lebenden Sprachen läßt sich Vergleichbares, soviel ich sehe, nicht beobachten. Hier tat der alte Ausdruck sich im Zeichen des Kreuzes schwerer. Vorübergehend hat er wohl zwischen vorchristlicher und christlicher Bedeutung geschwankt, zumindest regional; altkirchenslawisch begegnet trěba für »Gottes-» wie für »Götzendienst« und kann dabei auch jüdisches Opferwesen abdecken. Trěbnik zeigte sich fähig, zum Inbegriff eines liturgischen Handbuchs, eines "Euchologion", zu werden, und Trebni$c a /$ Trebnitz, im Ursprung wohl »Opferstätte«, konnte sich in gar nicht so wenigen Fällen als Ortsname halten, auch für Kirchplätze, ja Klosterstätten; dabei mag es im einzelnen schwierig sein, dergleichen Toponyme von Fällen zu trennen, in denen vielmehr »Rodeland " gemeint ist ${ }^{11}$. Im allgemeinen aber scheint das alte Substantiv zurückgedrängt; »Opfer» wird heute meist durch $\check{z}(e) r t v a / z ̌ r t e v ~ g e d e c k t$, einen anderen Begriff aus der

logiczny 25 (1978), S. 17, 19, 20 u. bes. 21 f., vgl. 24; DERS. (Hg.), Thesaurus Linguae Dravaenopolabicae III, Köln-Wien 1984, S. 1233 f., vgl. 1236. Der leider inzwischen verstorbene Herr Verfasser hat die vorliegende Studie in ihren Anfängen mit freundlichem Interesse begleitet und mir die zitierten Arbeiten noch selbst zur Verfügung gestellt; offene Fragen, bes. die teilweise Trennung der dravänopolab. Begriffe für »Dezember« und »Weihnachten«, konnten leider nicht mehr mit ihm diskutiert werden.

6 L. WEISER-AAL - A. SEIERSTAD, Jul, in: Kulturhistorisk Leksikon för Nordisk Middelalder VIII, København 1963, Sp. 6-17, vgl. O. JANSSON, Julmånad, ebd., Sp. 22 f. Als Unterschied ist festzuhalten, daß treba eine Kulthandlung bezeichnet, jul ein jahreszeitliches Fest. Vgl. auch de VRIES, S. 292 s.v. jól, bes. zu Nr. 6.

7 OLESCH 1976, S. 18; auf die Bedeutung der Kirchenprovinzen für die Entwicklung christlicher Terminologien im Deutschen verweist Th. FRINGS, Grundlegung einer Geschichte der deutschen Sprache, Halle/S. 1957, S. 18 f., vgl. 21-23 u. Karten 11-18 (S. 101-108); in Einzelheiten überholt.

8 s. Anm. 6 .

9 Vgl. noch unten bei Anm. 93-94.

${ }^{10}$ Die Befunde unten bei Anm. 87-88 führen auf eine kultische Handlung, nicht auf eine Festbezeichnung.

${ }^{11}$ F. MIKLOSICH, Die Bildung der slavischen Personen- und Ortsnamen. Neudruck Heidelberg 1924, S. 330 f. Nr. 692; vgl. R. TRAUTMANN, Die elb- und ostseeslawischen Ortsnamen II (Abh. d. Akademie. d. Wiss. Leipzig, phil.-hist. Kl. 1949/7), S. 90; E. SCHWARZ, Sprache und Siedlung in Nordostbayern (Erlanger Beiträge zur Sprach- und Kunstwiss. 4), Nürnberg 1960, S. 209-211; SSS VI (1980), S. 148-152 u. 185-191, passim; 
vorchristlichen Kultsprache, der sich, aus welchen Gründen immer, besser zu behaupten vermochte, obgleich er zeitweise ähnlich zwischen den Religionen schwankte ${ }^{12}$, mit Ausgangsbedeutung »loben«, die jedoch schon unter dem alten Kult erweitert war (der zeitweise versuchte Anschluß an žerti »fressen « wird bestritten $)^{13}$. Das Tschechische hat obět an die Stelle gesetzt, das von der Bedeutung »Gelübde « ausging ${ }^{14}$, das Polnische läßt ofiara eintreten, unverkennbar fremdentlehnt. Im alten trěba muß der »heidnische« Gehalt stärker gewesen sein als selbst für $\check{z}(e) r t v a$, so daß verchristlichte Sprache es nicht leicht auf Dauer zu ertragen vermochte, wo nicht Sonderverhältnisse mitsprachen; es ist dermaßen vergessen, daß selbst der Etymologe in einschlägigen Zusammenhangen gelegentlich nur noch an die gleichlautende Verbform erinnert, die auf »Nötiges « hinweist ${ }^{15}$.

\section{Eine Quelle im Irrgarten der Zuweisungsversuche}

Als ältester Beleg für die Bedeutung »Opfer« geistert durch die Literatur das Zitat, das mit der Form trebo aufwartet, immer wieder zurückgeführt auf »das Paderborner Kapitular vom Jahre $785^{16}$. Die Angabe greift eine Bezeichung auf, die zeitweise für die Capitulatio de partibus Saxoniae üblich war, das berüchtigte Blutgesetz, mit dem Karl. d. Gr. das Apostatentum der neuchristianisierten Sachsen einzudämmen suchte ${ }^{17}$. Die Form wäre damit in deren östlichem Vorfeld lokalisiert, gleichfalls in der Erzdiözese Mainz, in das gleiche Bistum Verden, in dessen Bereich das jüngere dravänopolab. tribe/trewe gehört, oder das benachbarte Halberstadt, nach heutigen Begriffen das nordöstliche Niedersachsen und das westliche Sachsen-Anhalt - Slawengebiete, von deren Einbeziehung in die Missionspolitik des Frankenherrschers wir sonst nichts wissen - ; trebo gehörte zu den ältestbezeugten slawischen Worten, belegt weit vor Ausbildung des Kirchenslawischen, wetteifernd mit dem zweiten der »Freisinger Denkmäler«, das einen weiteren frühen Beleg bietet, in einer um 1000 hergestellten Abschrift, doch mindestens im Kern gleichfalls karolingerzeitlich ${ }^{18}$. Im Text der Capitulatio allerdings sucht man die

GIEYSZTOR, S. 256 f., u.a. mit dem Hinweis, daß in Trzebiatów/Treptow (Pommern), dessen Name gleichfalls auf diesen Kult hinweisen könnte, Spuren einer Opferstätte ergraben wurden. Treptow kommt auch anderweitig, z. B. in Mecklenburg, vor. - MIKLOSICH 1876, S. 37, bringt für trêbište »Ort, wo geopfert « wird, S. 18, Nr. 17 f., außerdem die Bedeutung »Kirche«, die dort auch für trêbrniks aufscheint. Im Einzelfall hängt hier viel davon ab, ob unter den Schöpfern einer christlichen Terminologie vor Ort »Ireniker« oder »Polemiker" am Werk waren, wozu KAHL, S. 38.

${ }^{12}$ MOSZYŃSKI, S. $107 \mathrm{f}$.

${ }^{13}$ Ebd., Anm. 444.

${ }^{14}$ I. WIEHL, Untersuchungen zum Wortschatz der Freisinger Denkmäler. Christliche Terminologie (Slavist. Beitr. 78), München 1974, S. 87.

${ }^{15}$ SCHWARZ, S. 210 - Für die Entwicklung wird nicht belanglos gewesen sein, daß MIKLOSICH 1876, S. 36 Nr. 6, für treba sogar die Bedeutung "Götze« (= Empfänger des sonst so bezeichneten Opfers) verzeichnet.

${ }^{16}$ BRÜCKNER 1925 u. (1936) 1957 (wie Anm. 2); WACHTLÓWNA, S. 301; E. WIENECKE, Untersuchungen zur Religion der Westslawen, Leipzig 1940, S. 275; GIEYSZTOR, S. 251; MOSZYŃSKI, S. 109.

${ }^{17}$ Capitulatio de partibus Saxoniae, in: MGH Capitularia I, ed. A. Boretius, 1883, S. 68; längst nicht mehr bestimmt auf 785 datiert, vgl. bereits ebd., Vorbem. (mit Einreihung zu 775-790), und G. THEUERKAUF, Lex, Speculum, Compendium Juris. Rechtsaufzeichnung und Rechtsbewußtsein in Norddeutschland vom 8. bis zum 16. Jh., Köln-Graz 1968, S. 47 f., Anm. 43; H. MORDEK, Bibliotheca capitulariorum... (MGH Hilfsmittel 15), München 1995, S. 770. - Zur Einschätzung der Sachsen in fränkischem Verständnis als Apostaten seit ca. 777: H.-D. KAHL, Karl d. Gr. und die Sachsen, bei H. Ludat - R. Chr. Schwinges (Hgg.), Politik, Gesellschaft, Geschichtsschreibung. Gießener Festgabe füe F. Graus (Beih. z. Arch. f. Kulturgesch. 18), Köln-Wien 1982, S. 81-97, passim, vgl. bes. Anm. 98 ff. (S. 121 f.), dazu noch S. 96 f.

${ }^{18}$ S. unten bei Anm. 85-86 u. 113-119. 
fragliche Wendung vergeblich. Man stößt auf einen unverkennbaren Gedächtnisfehler, der durch die Autorität ALEKSANDER BRÜCKNERs gedeckt schien ${ }^{19}$. Dabei ist das Zitat griffig und aussagekräftig: idolothita quod trebo dicitur, definierend durch einen Ausdruck der Vulgata, die den Singular des griechischen Lehnworts, idolothytum, zweimal in eindeutiger Weise für »Götzenopfermahl« einsetzt ${ }^{20}$. Man läßt sich den Beleg ungern entgehen. Aber wo ist er zu finden?

Die Suche führt auf einen Text nicht des achten, sondern des zehnten Jahrhunderts, eher der ersten als der zweiten Hälfte angehörig - jedenfalls ein Abstand von mehreren Generationen. R. W. DOVE hat ihn, nachdem er schon länger bekannt war, 1864 erstmals kritisch ediert, A. M. KOENIGER 1907 nochmals nachgedruckt, beides an Stellen, für die verständlich ist, daß sie nicht fest in der Erinnerung blieben ${ }^{21}$. Doch wenn man die Quelle eindeutig benennen soll, stößt man auf Schwierigkeiten. Sprechen wir provisorisch von $»$ T .

Die Eingangsformel (Statutum est) weist auf einen Synodalbeschluß, die festgelegte Verfahrensweise ordnet ihn dem sog. Sendgerichtswesen zu. Dieses gehört zu den folgenreichsten kirchenrechtlichen Neuerungen, die die Karolingerzeit angebahnt hat, mit weitreichender Wirkung über Jahrhunderte hin. Das altdeutsche send, abgeleitet von kirchenlat. synodus, bezeichnet öffentliche Gerichtsverhandlungen unter dem Vorsitz von Bischof oder Archidiakon, durchgeführt an zentralen Kirchen des Pfarrsystems (»Sendkirchen«): T selbst spricht von synodica stipulatio. Sie sollten der Durchsetzung kirchlicher Anforderungen an Glaubensstand und Lebensführung des Gemeindevolks dienen, das bei der oberflächlichen Missionspraxis jener Zeit nur gar zu häufig nicht im voraus zu durchschauen vermochte, was für Konsequenzen der Übertritt zur neuen Religion in sich schloß. Es handelt sich mithin, und das darf nicht aus dem Blick geraten, grundsätzlich um Maßnahmen nicht der Mission, in der sich die Kirche nach außen wendet, sondern um solche innerkirchlicher Disziplinargewalt. Voraussetzung ist der rechtsverbindliche Taufvollzug, der die förmliche Aufnahme in die Gemeinschaft der Christen besiegelt; außerkirchliches Heidentum, das diesen Schritt noch vor sich hat, bleibt unberührt, da es dieser Disziplinargewalt nicht untersteht. Auch T setzt ausdrücklich Menschen voraus, die post perceptam baptismi gratiam leben, "nach Empfang der Taufgnade« - sie sind es, unter denen mit Verstößen der aufgelisteten Art aufgeräumt werden soll; über andere wird nichts gesagt ${ }^{22}$. Eine Synode wie die, auf die der Beschluß T zurückgeführt werden muß, war selbstverständlich von anderem Zuschnitt, nicht nur exekutiven, sondern legislativen Charakters. Dabei ist wichtig, daß solche Synoden damals keineswegs immer von andersartigen Gremien mit Beteiligung weltlicher Machthaber zu trennen sind ${ }^{23}$. Die Karolingerzeit und auf ihr aufbauende Jahrhunderte waren weit entfernt von klarer Trennung zwischen kirchlicher und weltlicher, staatlicher Sphäre. T bindet Grafen und

${ }^{19}$ BRÜCKNER 1925 u. (1936) 1957 (wie Anm. 2). Der Irrtum mag daran angeknüpft haben, daß die Capitulatio (wie Anm. 17), c. 22 (S. 22), ein gleichartiges Verbot der Bestattung von Toten bei oder in Hügelgräbern statt auf dem kirchlichen Friedhof festschreibt, vgl. unten vor Anm. 55.

${ }^{20}$ I. Cor. 8, 7; Apc. 2, 20.

${ }^{21}$ DOVE 1864 (s. Anm. 26); S. 160-162; KOENIGER I (s. Anm. 28), S. 194-196, Zur Datierung unten Anm. 68 sowie 112.

${ }^{22}$ Dazu KAHL, wie Anm. 3.

${ }^{23}$ Über die Schwierigkeit, für die Karolingerzeit kirchliche Synoden und andere Versammlungen klar zu trennen, vgl. z. B. I. SCHROEDER, Die westfränkischen Synoden von 888 bis 987 (MHG Hilfsmittel 3), München 1980, S. 7-11. 
weitere regionale oder lokale Machthaber in einer Weise ein, daß entsprechende Instanzen an der Beschlußfassung beteiligt gewesen sein müssen; sie könnte durchaus an einem königlichen Hoftag im Bezugsgebiet zustandegekommen sein.

Doch an welche Gegend ist zu denken? Für mache Passagen von T sind Vorlagen benannt worden, deren Wortlaut man eingearbeitet hat. Sie bieten ihrerseits Zuweisungsprobleme, auf die an dieser Stelle nicht eingegangen werden kann ${ }^{24}$. Der Abschnitt, auf den es hier ankommt, gehört nach bisheriger Kenntnis nicht dazu, und er fällt unter seinesgleichen durch eine Besonderheit auf. Das Sendgerichtswesen kennt zahlreiche Verordnungen, die in allgemeiner Form »heidnischen Aberglauben « brandmarken, etwa die Verehrung von Quellen, Bäumen oder Steinen. Damit sind dann Kultobjekte gemeint, die seit alters Verehrung heischten und für das Volksempfinden nicht so schnell aus diesem Anspruch verdrängt werden konnten. T geht anders vor: Vor dem Sendgericht anzuklagen ist unter anderem, wie die barbarische Konstruktion ausführt, qui idolothita, quod trebo dicitur, vel obtulerit aut manducavit - »wer die Götzenopfer, was man trebo nennt, darbringt oder ißt« - das zweite, streng genommen, gegen die biblische Weisung ${ }^{25}$. Das benennt nicht Kultobjekte, für die dabei die Art der Verehrung offen bleibt, sondern eine bestimmte Kulthandlung, und sie erhält ihren slawischen Namen, den weder Romanen noch Germanen kannten. Daß dafür aus den alten Gebieten des Frankenreiches und ihren Konzilien kein Vorbild bekannt ist, kann nicht erstaunen. Wir haben eine Angabe vor uns, die unmittelbar auf ein bestimmtes Bezugsgebiet geprägt ist, unabhängig davon, was etwa verallgemeinerungsfähig wäre. Mehr oder weniger schematische Übertragung von einem anderen Schauplatz her scheidet aus.

Aber gerade damit gelangen wir erneut in Teufels Küche. T erscheint in der Überlieferung ohne Inskription und Rubrum, ohne jeden Anhalt für Zeit und Ort des Beschlusses. Das versperrt den Zugang zu den ausschlaggebenden Hintergrundzusammenhängen. Eindeutig lesen wir von "Slawen" oder "Wenden" (Sclaui); sie sind als einziges Ethnicum namentlich erwähnt. Aber welche waren gemeint?

DOVE hat T das "Sendrecht der Main- und Rednitzwenden" genannt und damit ins erweiterte Obermaingebiet verwiesen ${ }^{26}$. S. RIEZLER - keineswegs ein Irgendjemand - fand Gründe, die weiter nach Süden führten, etwa in die heutige Oberpfalz ${ }^{27}$. Das ist noch eine relativ geringe Schwankung, zwischen zwei Nachbarbistümern: Würzburg in dessen ursprünglicher Ausdehnung, vor der Abscheidung Bambergs, und Eichstätt, beide Suffragane von Mainz. KOENIGER kehrte, ohne RIEZLERs Einwände zu entkräften, ins Maingebiet zurück und sprach vom »Würzburger Sendrecht $^{28}$, später allerdings, stark verallgemeinernd, vom »Slawensendrecht $«$ schlechthin ${ }^{29}$. ERNST MAYER faßte

${ }^{24}$ S. Anm. 112.

${ }^{25}$ I. Cor. $8,7$.

${ }^{26}$ R. DOVE, Untersuchungen über die Sendgerichte, in: Zschr. f. deutsches Recht 19 (1859), S. 382 ff.; DERS., Das von mir s. g. Sendrecht der Main- und Rednitzwenden, in: Zschr. f. Kirchenrecht 4 (1864), S. 157-175.

${ }^{27}$ S. RIEZLER, Bistum Eichstätt und sein Slavensendrecht, in: Forsch. z. deutschen Gesch. 16 (1876), S. 397-408; zustimmend. E. HERRMANN, Zur Assimilierung der Slawen in Ostfranken im Hochmittelalter, in: Arch. f. d. Gesch. von Oberfranken 48 (1968), S. 93.

${ }^{28}$ A. M. KOENIGER, Die Sendgerichte in Deutschland I, München 1907, S. 27 u.ö.; H.-D. KAHL, Einige Beobachtungen zum Sprachgebrauch von natio im mittelalterlichen Latein, bei H. Beumann- W. Schröder (Hgg.), Aspekte der Nationenbildung im Mittelalter (Nationes I), Sigmaringen 1978, S. 73, Anm. 25.

${ }^{29}$ A. M. KOENIGER, Vom Send, insbes. in der Diözese Bamberg, in: Jahrb. d. Hist. Vereins Bamberg 70 (1912), S. 35 (unter Zuweisung an die ältere Diözese Würzburg, ebd., S. 34); vgl. DENS., Slawen-Sendrecht in: Lexikon für Theologie und Kirche IX (1937), Sp. 634 (in die Neuauflage nicht wieder aufgenommen). 
stattdesssen das slawische Misssionsgebiet der Salzburger Kirchenprovinz ins Auge, weitab im Südosten, zwischen Donau und Drau ${ }^{30}$. Niemand versuchte eine Entscheidung. So erklärt sich wohl, daß z.B. ein wichtiges Handbuch für »Die Slawen in Deutschland « den instruktiven Text, offenbar als nicht hergehörig, übergeht ${ }^{31}$. Auch JOSEPH SCHÜTZ hat im Quellenanhang zu seiner Untersuchung von »Frankens mainwendische(n) Namen « auf T verzichtet ${ }^{32}$. Andererseits waren MAYERs Argumente nicht stark genug, um der Quelle Eingang in das Schrifttum zum Wirkungsfeld der Salzachmetropole zu verschaffen ${ }^{33}$. ERWIN HERRMANN ${ }^{34}$ und JERZY NALEPA ${ }^{35}$ blieben trotz allem in den Grenzen des heutigen Bayern, kamen jedoch weder zu neuen Lösungen noch zu einhelligem Urteil. Fazit: Verunsicherung. Einzig darin sind die konkurrierenden Zuweisungsvorschläge sich einig, daß keiner für Gebiete nördlich des Thüringer Waldes eintritt, wie BRÜCKNERs Fehlangabe sie nahezurücken schien. Sie dürfen bis zum Auftauchen entsprechender Argumente auch weiterhin ausgeklammert beiben.

Prüft man die Versuche am heutigen Forschungsstand, so ist festzustellen: Gegen MAYER sprach von Anfang an, daß zu in Betracht kommender Zeit die Salzburger Kirchenprovinz am Sendgerichtswesen noch nicht erkennbar teilgenommen hat ${ }^{36}$. Daß von $\mathrm{T}$ benutzte ältere Textpartien auch in Salzburger Überlieferung aufscheinen, war ein dankenswerter Hinweis, kann jedoch dieses Grundfaktum nicht aus den Angeln heben; gerade die wichtigsten, charakteristischsten Bestimmungen sind dort bisher nicht nachgewiesen worden. Andererseits wissen wir inzwischen, daß der bedeutendste Handbuchautor des Sendgerichtswesen, Bischof Burkhard von Worms (1000-1025), seine Sammlungen nachträglich neu redigierte, nachdem er umfangreiches Zusatzmaterial aus Freising bekam, d.h. von einem Salzburger Suffragan, der im südöstlichen Slawenland missionarisch und sonst besonders intensiv tätig gewesen ist ${ }^{37}$. Die entscheidenden Abschnitte von $\mathrm{T}$ tauchen in der Gesamtüberlieferung von Burkhards Werk, über 80 Handschriften, nur zweimal auf, und dann als Extravaganten, Nachtragsbestände fremden Ursprungs - darauf ist gleich zurückzukommen. Wie wir den Autor kennen, hätte er sich einen Text wie T nicht entgehen lassen. Er hat ihn also nicht gekannt, und dasselbe gilt offenbar für die Freisinger.

${ }^{30}$ E. MAYER, Das sog. Sendweistum der Main- und Rednitzwenden und andere Quellen des bayrischen Kirchenrechts aus dem Ende des 9. u. Anfang des 10. Jh. s., in: Zschr. f. Bayer. Landesgesch. 6 (1933), S. 1-26 (Wiederabdruck aus Arch. d. Hist. Vereins f. Unterfranken 68, 1929, S. 435-446); dazu bereits E. HERRMANN (wie Anm. 27), S. 93, sowie KAHL 1978, S. 73. Anm. 26.

${ }^{31}$ H. WALTHER, Die Slawen westlich von Elbe/Saale und Böhmerwald unter fränkischer und deutscher Feudalherrschaft, bei J. HERRMANN (Hg.), Die Slawen in Deutschland. Ein Handbuch, Neubearbeitung, Berlin 1985, S. 349-355.

${ }^{32}$ J. SCHÜTZ, Frankens mainwendische Namen. Geschichte und Gegenwart, München 1994, S. 202-219. Entsprechend SCHWARZ (wie Anm. 11), S. 356-362.

${ }^{33}$ Vgl. nur die Darstellung der Salzburger Slawenmission bei H. DOPSCH, Geschichte Salzburgs I/1, Salzburg 1981, S. 174-187, und C. FRÄSS-EHRFELD, Geschichte Kärntens I, Klagenfurt 1984, S. 60 ff. 98 ff. u.ö.

${ }^{34}$ E. HERRMANN (wie Anm. 27) S. 92-97.

${ }^{35}$ J. NALEPA, Bawaria - Słowianie w Bawarii, in: SSS I (1969), S. 97.

${ }^{36}$ KOENIGER I, S. $186 \mathrm{f}$.

${ }^{37}$ Freising hat bekanntlich über die Hautptstützpunkte Innichen (Südtirol) und Maria Wörth/Otok (Kärnten) wesentlich mehr zur Christianisierung von Oberkärnten mit Osttirol beigetragen als Salzburg. Später wirkte es von Škofja Loka/Bischoflack (Slowenien) aus intensiv auch in Krain. Die »Freisinger Denkmäler«, in der Bischofsstadt überliefert, gehören zu den ältesten slawischen Sprachzeugen. - Über Burkhard und Freising: H. HOFFMANN - R. POKORNY, Das Dekret des Bischofs Burchard von Worms. Textstufen - frühe Verbreitung - Vorlagen (MGH Hilfsmittel 12), München 1991, S. 164 f. - Hier und im folgenden verwerte ich dankbar Hinweise von Herrn Prof. Dr. Theo KÖLZER, Bonn. Zu E. MAYER noch oben Anm. 30. 
Unser neues Wissen zur Überlieferungsfrage berührt jedoch auch RIEZLERs Thesen. Von den beiden Codices, die T mitteilen, stammt derjenige, den wir inzwischen als den älteren kennen, aus der Dombibliothek von Eichstätt. Bereits unter Bischof Gundekar II (1057-1075) war er dort vorhanden; mainfränkische Provenienz ist nicht ausgeschlossen, doch auch baierische Herkunft möglich, zumindest für die Person des Schreibers der Partien, auf die es ankommt ${ }^{38}$. Die andere Handschrift kommt aus der Dombibliothek von Konstanz und ist wohl wenig später im dortigen Scriptorium entstanden ${ }^{39}$. Die zugehörige Diözese erstreckte sich vom Bodenseegebiet weit nach Süden über alemannisch-ladinische Bevölkerung. An Fragen der Slawenmission war das Bistum nicht interessiert - T kann nicht dort konzipiert worden sein. Eichstätt hingegen hatte, wie erwähnt, auch Slawengebiete unter sich. Die Versuchung war groß, den Ursprung des Synodalbeschlusses dort zu suchen, zumal eine Bestimmung den $d u x$ betrifft. Das wurde lange schematisch mit »Herzog« übersetzt, und einen solchen hat es in Ostfranken niemals gegeben, wohl aber in Altbayern, und er kann durchaus auch im Eichstätter Bereich Einfluß genommen haben ${ }^{40}$.

Das letzte Argument zieht nicht mehr, seit wir gelernt haben, daß es »Herzöge« im späteren, reichsrechtlichen Sinne vor Mitte 10. Jh.s gar nicht gab und folglich auch keine offizielle Bezeichnung für diesen Rang. Dux, das sich schließlich als solche fixierte, war vorher für längere Übergangszeit ein möglicher, doch keineswegs ein stehender Ausdruck für Machtträger, die eine Ebene zwischen Grafen und König erreicht hatten: gehobenen königlichen Amtsauftrag, etwa durch Kumulation von gräflichen Funktionen, verbunden mit ausgedehnten Gebietsherrschaften, auch wenn diese nicht geschlossen und keineswegs an Stammesgrenzen gebunden waren. In der älteren, weitergespannten Francia orientalis, in der Mainfranken und Rheinfranken sich noch nicht gesondert hatten, besaßen eine solche Stellung zwischen dem Ende der Babenberger Fehde (906) und dem Tod des Königsbruders Eberhard (937) konkurrenzlos die Konradiner. Ihre Hauptrepräsentanten, sowohl Konrad, nachmals König, wie dieser Bruder, werden ausdrücklich $d u x$ genannt, zwar selten, doch bei der allgemein schlechten Überlieferungslage, und da ein gefestigter Sprachgebrauch noch fehlte, muß das nicht stören ${ }^{41}$. Es führt jedoch in eine Zeitspanne, die für die Entstehung von T sehr wohl in Betracht kommt. Beide Würdenträger dürften auch, wie T das nahezulegen scheint, Lehnsherren von Grafen gewesen sein, sei es, daß es ihnen gelungen war, solche von königlicher Ein-

${ }^{38}$ Eichstätt, Universitätsbibliothek, Cod. st 772 (früher ebd., Diözesanarchiv, MS 6, aus Seminarbibliothek, MS 48); dazu ausführlich HOFFMANN-POKORNY, S. 129 u. 136-143.

${ }^{39}$ Freiburg i. Br., Universitätsbibliothek, Hs 7 (früher wohl Konstanz, Dombibliothek); dazu H. HOFFMANN, Buchkunst u. Königtum im ottonischen u. frühsalischen Reich (Schriften der MGH 30/1), Stuttgart 1986, S. 208 f.; vgl. HOFFMANN-POKORNY, S. 129 dazu 68 m. Anm. 23.

${ }^{40}$ RIEZLER und E. HERRMANN, wie Anm. 27.

${ }^{41}$ H. -W. GOETZ, »Dux« und »Ducatus«. Begriffs- und verfassungsgeschichtliche Untersuchungen zur Entstehung des sog. jüngeren Stammesherzogtums an der Wende vom 9. zum 10. Jh., Bochum 1977 (mit detaillierter Untersuchung des Sprachgebrauchs je für die einzelnen Quellenautoren); M. BECHER, Zwischen König und »Herzog«, bei F. FUCHS - P. SCHMID (Hgg.), Kaiser Arnolf. Das ostfränkische Reich am Ende d. 9. Jh. (Zschr. f. Bayer. Landesgesch., Beiheft 19), München 2002, S. 94-98 m. weiterer Lit. Zu den konradinischen $d u x$-Titeln bereits E. DÜMMLER, Geschichte des ostfränk. Reiches III, 2. Aufl. Leipzig 1888 = Darmstadt 1960, S. 542 m. Anm. 2 sowie S. 568 m. Anm. 1; vgl. auch K. BRUNNER, Die fränkischen Fürstentitel im 9. u. 10. Jh., bei H. Wolfram (Hg.), Intitulatio III, Wien 1973, bes. S. 307, sowie G. LUBICH, Auf dem Weg zur "Goldenen Freiheit«. Herrschaft und Raum in der Francia orientalis von der Karolinger- zur Stauferzeit (Histor. Studien 449), Husum 1996, S. 47 m. Anm. 89, S. 55 f. m. Anm. 135 und S. 59 ff. 
setzung zu mediatisieren, oder daß sie in eigenen Grafschaften Stellvertreter einsetzten, für die gleichfalls comes vorkommen $\mathrm{kann}^{42}$. Sichere Kenntniss in Details dieser Art bleibt uns versagt. Wir kennen Grafschaften, wissen aber nicht für jeden Zeitpunkt zu sagen, wer sie damals innehatte.

Bleibt die Eichstätter Provenienz des einen, vielleicht älteren der beiden Codices. Allerdings darf sie als Überlieferungszufall bewertet werden, der weitergehende Schlüsse ebensowenig zuläßt wie das Konstanzer Gegenstück. Beide Handschriften bringen den Text zwar im Rahmen von Burkhards Dekretaliensammlung, für die sie verhältnismäßig frühe Textzeugen sind, beide jedoch als sog. Extravagante, d.h. als zusätzliches Überlieferungsgut, das sonst nirgends auftaucht. Schon DOVE hat beobachtet, daß T hier wie dort an derselben Stelle erscheint, im unmittelbaren Anschluß an das letzte Kapitel des ersten Buches, und in beiden ist die Hand jeweils identisch mit derjenigen, die die vorausgehenden Textpartien schrieb; für Eichstätt darf hinzugefügt werden, daß es auch dieselbe Hand war, die die anschließenden Partien lieferte, in diesem Fall die Kapitelübersicht für Burkhards zweites Buch; dabei hat der Schreiber unterschätzt, wieviel Raum er für deren in anderer Tinte auszuführenden Titel aussparen mußte, so daß dieser sich nachträglich mühsam einzuzwängen hatte. Hinzuzunehmen ist, daß T vom Inhalt her weder zum vorausgehenden ersten noch zum folgenden zweiten Buch paßt; erst das zehnte, allenfalls das elfte hätte einen angemessenen Platz geboten.

Für beide Überlieferungen ergibt sich damit ein eindeutiger Befund. Er besagt: $\mathrm{T}$ ist nachträgliche Einfügung, von Burkhard selbst nicht vorgesehen (sonst erschiene sie auch noch in jüngeren Redaktionen seines Sammelwerks); der Nachtrag kann jedoch weder im Eichstätter noch im Konstanzer Scriptorium selbständig vorgenommen worden sein - beide Schreiber müssen ihn bereits in ihrer Vorlage vorgefunden haben. Dies mag derselbe Codex gewesen sein oder jedesmal eine anderer, nahe verwandt aus gleicher Filiation - das läßt sich bisher nicht bestimmen. Nachgewiesen ist keiner, der in Betracht kommen könnte; mit Verlust ist zu rechnen ${ }^{43}$. Vermutet werden darf, daß der Zusatz das erste Mal auf zufällig frei verfügbarem Platz, etwa an einem Lagenende ${ }^{44}$, im Scriptorium desjenigen Bistums erfolgte, für das dieser Synodalbeschluß zustandekam, und dort an abgehobener Schrift kenntlich wäre, wenn wir diesen Codex noch hätten. Das jedenfalls würde am besten verständlich machen, warum, anders als üblich, jede Herkunftsangabe unterblieb. Um welches Bistum es sich dabei aber handelte, gibt uns niemand preis. Es kann nur aus Indizien erschlossen werden.

Dabei hilft uns T selbst mit einem weiteren Passus, der bisher nicht gebührend gewürdigt wurde. Im unmittelbaren Anschluß an die schon herausgehobene Partie, die trebo nennt, erscheint als weiterer Anklagepunkt: qui mortuos non in atrio ecclesiae, sed ad

${ }^{42}$ Der Sprachgebrauch comes = »Untergraf $«$ wird wenig beachtet. Am bekanntesten der Fall des Ministerialen (!) der Grafen von Stade, Friedrich, um 1100, vgl. W. PETTKE, Friedrich Nr. 40, in: Lexikon des Mittelalters (künftig: LMA) IV (1989), Sp. 961. Bedingt zu vergleichen sind Königstitel wie der böhmische, die im Ursprung für Unterkönige des deutschen galten. Wurden diese, nicht übertragbar, rechtsförmig verliehen, so blieb comes »Untergraf, Grafschaftsverwalter« offenbar auf erzählende Quellen beschränkt und erlosch, als comes wie dux im Lauf des 12. Jh. vom Amts- zum Geburtstitel wurde.

${ }^{43}$ O. MEYER, Überlieferung und Verbreitung des Dekrets des Bischofs Burchard von Worms, in: Zschr. f. Rechtsgesch. 75, Kanonist. Abt. 24 (1935), S. 152-155, 163 f. u. 180-183; G. FRANSEN, Le Décret de Burchard de Worms, ebd. 63 (1977), S. 13 f.; HOFFMANN-POKORNY, S. 129.

${ }^{44}$ O. MEYER, S. 181 f.; zu derartigen Eintragungen auch O. REDLICH, Über bairische Traditionsbücher und Traditionen, in: Mitt. d. Öst. Inst. f. Geschichtsforsch, 5 (1884), S. 35 f. - Auch die Freisinger Denkmäler sind auf solche Weise überliefert. 
tumulos, quos dicimus more gentilium hougir, sepelierit - »wer Tote nicht auf dem Friedhof bestattet, sondern bei (oder: in) den Hügeln, die wir nach Heidenweise hougir nennen.« Da erscheint als Pendant zu dem slawischen Wort ein althochdeutsches, offenbar aus der Sprache jener ceterae nationes, die T außer den Slawen anführt; der Ausdruck ist der herrschenden Schicht bekannt, gehört aber offenbar nicht zu ihrem eigenen Sprachschatz - deshalb wird nicht ein Terminus wie vulgariter eingesetzt, wie er sonst die eigene Volksprache kennzeichnet im Gegensatz zum gelehrten Latein, sondern es wird auf ein Außenseitertum angespielt, das als »heidnisch « empfunden werden konnte ${ }^{45}$. Hougir ist Plural zum Neutrum houc (Stamm houg-). Dieses Wort, mit Hügel verwandt, samt seinen Entsprechungen in anderen germanischen Mundarten zeigt eine eigenartige geographische Verbreitung. Es begegnet in den skandinavischen Ländern und strahlt über Wikingereinfluß nachEngland, ja in bestimmte Teile Frankreichs aus. In Deutschland erscheint es so auffällig inselhaft, daß an Zusammenhänge mit der Verschiebung von Volkssplittern in der Völkerwanderungszeit gedacht worden ist, zumal das Vorkommen sich bemerkenswert mit dem eines eigenartigen Ortsnamentyps deckt, der Toponyme auf -leben. Es erlischt südlich des Maingebietes und des nördlichen Odenwaldes. Selbst schwache Spuren, wie die Beharrsamkeit von Flurnamen sie sonst auch dort festzuhalten pflegt, wo ein Wort der lebendigen Sprache verlorengegangen ist - selbst solche Spuren fehlen weiter nach Süden hin. Stattdessen herrscht dort für die gleiche Bedeutung ein anderer Ausdruck, althochdeutsch hlêo, mittelhochdeutsch $l \hat{e}^{46}$. Dabei ist zu beachten: Die Überlieferung für houc und seine Nachfolgeformen besteht mehrheitlich nur noch aus Namengut. In T erscheint das Wort noch als Ausdruck lebendiger Sprache: nicht nur als Traditonselement, das mehr oder weniger gedankenlos weitergegeben wird, sondern als Appellativum; dabei in einer Pluralform, die vom althochdeutschen Normbestand her unregelmäßig ist - sie erinnert jedoch an die haugar des Altwestnordischen.

Entscheidend im buchstäblichen Sinn bleibt hier das Maingebiet als südliche Verbreitungsgrenze des Wortes. Gerade in der Karolingerzeit hat es dort besonders deutliche Spuren hinterlassen, etwa in den berühmten Markbeschreibungen von Hammelburg und Würzburg; das Stift Haug im heutigen Würzburger Stadtgebiet hält den Namen bis zur Gegenwart fest ${ }^{47}$. Südlichere Gegenden aber sind nach diesen Befunden auszuscheiden. Das betrifft vor allem die Thesen von ERNST MAYER; doch auch die Diözese

${ }^{45}$ Vgl. Capitulatio (wie Anm. 17) c. 21 (S. 69, 39), gegen Kultübungen more gentilium, wechselnd mit more paganorum u. ä. in früheren Kapiteln. - Vgl. Alcuin, ep. 3, c. 19 (MGH EE II, S. 27 ff).

${ }^{46}$ K. BISCHOFF, Germ. *haugaz »Hügel, Grabhügel« im Deutschen, Abh. d. Mainzer Akademie d. Wiss. 1975/4, dazu DERS., Germ. ${ }^{\star}$ hlaiw- „Grabhügel, Grab, Hügel« im Deutschen, ebd. 1979/3, dazu die Rezension von beiden durch J. KOIVULEHTO, in: Beiträge zur Gesch. d. deutschen Sprache u. Literatur 103 (1981), hier bes S. 102. Vgl. W. EMMERICH, Die siedlungsgeschichtl. Grundlagen, bei H. PATZE - W. SCHLESINGER (Hgg.), Geschichte Thüringens I (Mitteldeutsche Forschungen 48/I), Köln-Graz 1968, S. 312 m. Anm. S. 428; G. ROSENKRANZ, Die Bedeutung von Namen- u. Mundartkunde für die Ethnogenese der Thüringer, bei H. Wolfram - W. Pohl (Hgg.), Typen der Ethnogenese I (Denkschr. d. Öst. Akademie d. Wiss., phil.-hist. Kl. 201), Wien 1990, S. 86 f., mit im folgenden starker Betonung alter mainfränkisch-thüringischer Verbindungen. - Zur Ergänzung: de VRIES (wie Anm. 1), S. 213 f. s.v. haugr, vgl. O. BØ - S. LINDKVIST, Haugleggning, in: Kulturhist. Leksikon (wie Anm. 6), Sp. 246-250.

${ }^{47}$ BISCHOF 1975, S. 61, mit weiteren Belegen aus Ober- und Unterfranken; vgl. DENS. 1979, S. 18 m. Anm. 103104; SCHWARZ (wie Anm. 11), S. 163, vgl. 352; die Beispiele aus Mainfranken ließen sich mehren. Zum Stift Haug: A. WENDEHORST, Das Bistum Würzburg I (Germania Sacra NF 1), Berlin 1962, S. 85; W. SCHICH, Würzburg im Mittelalter, Köln-Wien 1977, S. 119. Herausragende Hügelgräber kamen auf mainfränkischem Boden u.a. in Zeuzleben bei Schweinfurt und bei Weismain (Kr. Lichtenfels) zutage; wie weit sie jemals als houc bezeichnet wurden, steht dahin. 
Eichstätt wird man danach nicht mehr in Erwägung ziehen dürfen. Wir haben offenbar beim mainfränkischen Würzburg zu bleiben. Ein verschollener Codex, gleichgültig, wo entstanden, der zur dortigen Dombibliothek gehörte, wird es gewesen sein, der T als erster aufnahm und auf welchen Wegen immer die weitere Überlieferung möglich machte. Der zugrundeliegende Synodalbeschluß hätte folglich dasselbe Zielgebiet betroffen, für das noch 1059, dann in der abgeteilten Diözese Bamberg, ein vielgenannter Entscheid gleicher Art eine mehrheitlich slawische Bevölkerung voll Hinneigung zu heidnischen Gebräuchen und voll Widerwillen gegen die christliche Religion bezeugt, was immer das zweite meinen will (ritibus gentilium dedita, abhorrens a religione christiana) ${ }^{48}$. Sämtliche Daten zur Bevölkerungs-, Sozial- und Verfassungsgeschichte, die T reichlich hergibt, vertragen sich mit dieser Annahme. ${ }^{49}$ Selbst das slawische Opferwort, ob es nun für diese Gegend mit treba oder trebo anzusetzen ist, findet sich dort wenigstens indirekt bezeugt, allerdings in einem problematischen Beispiel, das einige Aufmerksamkeit verlangt.

Schon oben wurde der Name Trebgast erwähnt. Er begegnet in Oberfranken dreimal: für einen Ort bei Kulmbach, am Weißen Main; für ein Flüßchen, das dort einmündet, und im (erloschenen) Altentrebgast, aufgegangen in der Bayreuther Vorstadt St. Johannis, am Roten Main. Eine Tradition, die bis zur Mitte des 19. Jahrhunderts, auf FRANZ MIKLOSICH zurückgeht, führt Toponyme dieses Typs auf Personennamen zurück, die mit altslaw. - gostb gebildet sind, einer Entsprechung zum germanisch-deutschen gast. Sie wurde für Trebgast u.a. von ERNST SCHWARZ vertreten, der dabei an Trebogost als Dorfherrn der Gründungszeit dachte; für das Gewässer faßte er eine Weiterbildung ins Auge, die im Deutschen nicht mehr kenntlich wäre, mit dem bekannten Zugehörigkeitssuffix - jb. Das wäre Ort und Fluß des genannten Mannes. JOSEPH SCHÜTZ entgegnete, wie das seinem Stil entsprach, mit scharfer Polemik. Er wies darauf hin, daß gostb ein maskuliner - $i$-Stamm ist, wie das deutsche Gast, während das Suffix $-j b$ sich nur mit maskulinen $-o$-Stämmen verbinde. Einen solchen, der hier in Betracht kommen könnte, fand er am besten in altpreuß. gasts repräsentiert, das »Flurstück, Feld, Feldmark« bedeutet. Altslawische Entsprechung wäre ${ }^{\star}$ gostz. Allerdings konzentrieren seine Darlegungen sich auf dieses Zweitglied, das Bestimmungswort der fraglichen Namengruppe, die in Oberfranken auffällig zahlreich begegnet. Deutungen für vollständige Toponyme bringt er fast gar nicht bei. Aus verstreuten Andeutungen darf man sich zusammensuchen, in welcher Richtung seine Vorstellungen sich bewegt haben könnten, ohne Sicherheit, wie weit man seine Position damit wirklich trifft. Das gilt auch für

${ }^{48}$ Druck bei Ph. JAFFÉ (Hg.), Bibliotheca Rerum Germanicarum V, Berlin 1969, S. 497; gekürzte Neuedition mit weniger geglättetem Text bei E. HERRMANN (wie Anm. 27), S. 101 f.; auch SCHÜTZ, S. 216 ff. mit Übersetzung; vgl. E. Frh. v. GUTTENBERG, Die Regesten der Bischöfe und des Domkapitels von Bamberg I, Würzburg 1932 = 1962, Nr. 312 (S. 144 f.) mit Mißverständis des compellerentur intrare als Taufzwang statt als Nötigung von Abweichlern zur Rückkehr in kirchliche Normen; dies übernimmt noch SCHÜTZ, a. O., obwohl er das Richtige bereits bei HERRMANN hätte finden können, dessen Arbeit er zitiert und benutzt; vgl. auch DENS., Zur mittelalterl. Siedlungsgesch. Oberfrankens, in Jahrb. f. fränk. Landesforsch. (künftig: JFLF) 39, 1979, S. 15 f.; R. ENDRES, Das Slawenmotiv bei der Gründung des Bistums Bamberg, in: 109. Bericht des Hist. Vereins... Bamberg, 1973, S. 173-182; H. JAKOB, Beiträge zum Paganismus der Main- u. Rednitzwenden, in: V. Setschkareff u.a. (Hgg.), Ars philologica Slavica. Festschr. H. Kunstmann (Sagners slavist. Sammlung 15), München 1988, S. 214-230, hier bes. S. 219 ff. (unverdient wenig beachtet; die Kenntnis dieser Arbeit danke ich Herrn PD Dr. HANS LOSERT, Bamberg). Weiteres bei Hartm. HOFFMANN, Mönchskönig und rex idiota. Studien zur Kirchenpolitik Heinrichs II. und Konrads II. (MGH Studien und Texte 8), Hannover 1993, S. 94 f., wozu noch unten bei Anm. 104-110.

${ }^{49}$ Dies entsprechend detailliert darzulegen muß anderer Gelegenheit vorbehalten bleiben. 
Trebgast. Gelegentlich, in Verbindung mit einem anderen Typ, findet sich ein Hinweis auf Rodungsnamen, die auch das Mainslawische vom Stamme treb-gebildet zu haben scheint. Hat er also an ${ }^{\star}$ Trěbogostı »Rodeland «bzw. den zugehörigen Bach gedacht? Er träfe sich dann mit SCHWARZ insofern, als auch dieser für das Erstglied des Namens die hier behandelte Wurzel trěb- im Auge gehabt hatte, nur in anderer Bedeutung, durch vergleichenden Hinweis auf die Verbform treba »es muß«, den SCHÜTZ, den Vergleichscharakter verkennend, mit unnötiger Ironie ad absurdum zu führen suchte ${ }^{50}$. Daß dieser Stamm auch ein altes Kultwort bildete, zieht keiner der beiden Kontrahenten heran.

Verbirgt sich also in Trebgast ursprünglich ein »Opferplatz« und entsprechend das "Gewässer, das zu diesem gehört«? Mehr als die Frage wird man einstweilen nicht wagen, so sinnvoll eine solche Bildung scheinen mag, und man wird sie mit einer gehörigen Portion Skepsis verbinden. Denn erstens geht in der Sprachentwicklung nicht alles nach unverbrüchlichen Gesetzen zu-immer wieder gibt es Analogiebildungen, die sich an sie nicht scheren-, und zweitens verfügen die slawischen Sprachen für diese Bedeutung über einfachere Bildungen wie trěbiste/trěbnik usw., die sprachgeschichtlich doch wohl älter sind; sie machen fraglich, ob für eine nachträgliche Zusammenfügung wie *trěbogostz »Opferplatz« wirklicher Bedarf bestand. Da bleibt also noch manches zu prüfen. An dieser Stelle darf genügen, daß das Vorkommen des Wortstamms, der treba/trebo hervorbrachte, für das Mainslawische von keiner Seite bestritten wird. Wenn aber Trebgast trotz SCHÜTZ vom Namen des Gründers und ältesten Dorfherren abzuleiten ist, dann dürfte dessen Anknüpfung an eine sakrale Gegebenheit sehr viel mehr Wahrscheinlichkeit haben als die an "Nötigung" oder an "Rodung", und seine Bewahrung mit diesem Element paßte nicht schlecht zum zähen Fortleben der kirchlich bekämpften idolothita. Auffällig rückte dann der Ortsname sogar in eine gewisse Nähe zu einem anderen der gleichen Kulmbacher Gegend. Weiter nach Westen hin liegt $\mathrm{Al}$ ladorf, älter Alachtorf, heute Ortsteil von Thurnau - ein langgezogenes Haufendorf mit einem Grundbestand von etwa 10 Höfen und dem grösten Reihengräberfeld bisheriger Kenntnis in Nordostbayern, belegt im 8. und 9. Jh. Der Ortsname ist weithin isoliert und wirkt altertümlich. Er dürfte in jene Zeit zurückreichen, denn sein Erstglied ist althochdeutsch schon am Verklingen; es kommt nicht mehr selbständig vor, auch wo man dies erwarten könnte - nur Namengut beweist noch sein einstiges Vorhandensein. Alach wird zum gleichlautenden altsächs. alah gestellt, Entschprechung zu got. alhs, altengl.

${ }^{50}$ E. Frh. v. GUTTENBERG, Land- u. Stadtkreis Kulmbach (Historisches Ortsnamenbuch von Bayern/Oberfranken I), München 1952, S. 166 f.; VOIT (wie Anm. 52), bes. S. 73 f.; SCHWARZ, bes. S. 208-210, passim, sowie S. 310, vgl. 213, 240, 243, auch 267 u. 334; SCHÜTZ (wie Anm. 32), S. 20-27 u. 34-40, passim, dazu S. 116 für Treppendorf/Trebesdorf ohne Verknüpfung mit vorliegendem Problem. Ausführlicher DERS., Die "fränkischen « Namen auf -gast, in: JFLF 48 (1988), S. 191-205, gleichfalls ohne Eingehen auf Treb-. Die eigenen Etymologien dieses Autors, stets geist- und kenntnisreich fundiert, sind oft weit hergeholt; daß sie nicht durchweg ins Schwarze treffen, vgl. KAHL (wie Anm. 53). - Über die Trebgast: E. WIEDEMANN, Besitzverhältnisse im oberen Trebgasttal, in: Arch. f. Gesch. Oberfrankens 49 (1969), S. 7-61; über Altentrebgast: DERS, Vetus Trebgast, ebd. 57 (1977), S. 409-421, vgl. E. HERRMANN 1979, S. 8 f. sowie 10 f. m. Anm. 49; ebd. S. 14 Hinweis auf ein karolingerzeitliches Gräberfeld bei Trebgast. Zu beachten ist, daß die Forschung für slaw. Gewässernamen auf -gošč auch noch erheblich andere Wege einschlägt, vgl. MOSZYŃSKI, S. 77 f. m. Anm. 305-306 (Lit.). Hier besteht offenbar noch reichlich Diskussionsbedarf, der auch auf Ort und Bach Trebgast zurückwirken könnte. Das hier wichtige Erstglied wird davon höchstens in semantischer Hinsicht berührt, die, wie oben gezeigt, vielfältige Möglichkeiten offen läßt. - Nicht vorgelegen hat E. EICHLER, Die deutschslavischen Ortsnamen auf -gast, in: Blätter f. oberdeutsche Namenforsch. 26 (1989), S. 7-10; vgl. aber DENS. bei W. Janka, Slawische Namen in Nordbayern, in (Hoops) Reallexikon d. germ. Altertumskunde, 2. Aufl. XXII (2003), S. 255. 
alh/ealh, und bedeutet zunächst »(vorchristliches) Heiligtum«. Die Kirche des Ortes, 1445 als Filiale von Trumsdorf gennant, ist archäologisch nicht untersucht. Sie zeigt jedenfalls eine bemerkenswerte Randlage, nur 200 m vom Gräberfeld entfernt, auf das sie jedoch nicht bezogen ist, denn beide werden durch einen Bacheinschnitt getrennt. Sie trägt ein wenig altertümliches Patrozinium (St. Nikolaus). Ein frühmittelalterlicher Vorgängerbau ist an Hand solcher Daten nicht unbedingt zu erwarten, wenn auch nicht von vorn herein auszuschließen.

Ältere Forschung wollte in Alladorf wegen des altertümlichen Namens ein Relikt einstiger Thüringersiedlung am Obermain sehen. Neuere Vorschläge fußen auf der Annahme, in Ortsnamen repräsentiere das Element Ala(c)h-jüngere Stadien der Bedeutungsentwicklung, die allerdings nur hypothetisch erschlossen, nicht ausdrücklich belegt sind. Gennant wurden »fränkische Militärsiedlung" (abgeleitet von »etwas, was Schutz gewährt«) und andererseits, schlichter, »Holzkirche«. Beide sind interessant begründet, stoßen jedoch auf Schwierigkeiten, die hier nicht alle erörtert werden dürfen.

Am gewichtigsten sind die Befunde des Gräberfeldes. Von Pfeilspitzen abgesehen, die auf Jagd deuten werden, hat es nichts an Waffen erbracht, im übrigen weder Fränkisches noch Christliches, wohl aber Hinweise, daß während der Gesamtdauer der Belegung kontinuierlich an den Skeletten wiederchristliche Praktiken vorgenommen worden sind, offenbar von ritueller Bedeutung. Zwei Pfostengruben wurden aufgedeckt, ließen sich aber in keinen Zusammenhang bringen, als gehörten sie zu einem gemeinsamen Grundriß; vielleicht repräsentieren sie getrennte hölzerne Memorialbauten über herauszuhebenden Bestattungsplätzen. All das paßt zu keiner der jüngeren Namensdeutungen, und so verdient mindestens für diesen Platz die ältere weiterhin den Vorzug; Alachtorf stünde dann ähnlich neben Trebgast wie in $\mathrm{T}$ die hougir neben trebo, Zeugen einer übersprachlichen regionalen Gemeinsamkeit ${ }^{51}$.

${ }^{51}$ v. GUTTENBERG, Kulmbach, S. 3 f. s.v., vgl. S. 101 s.v. Lochau sowie S. $17^{\star}-18^{\star}$ samt Kartenbeilage, dazu SCHWARZ, S. 167 u. 394 mit S. 53 u. 87-90, sowie E. HERRMANN 1979, S. 3 f. u. 7. Ortsnamenparallelen in Thüringen: G. BEHN-BLANCKE, Germanische Kultorte im Spiegel thüringischer Ortsnamen, in: Ausgrabunge u. Funde 9 (1964), S. 257 f., dazu FEIST (wie Anm. 1), S. 36 f. s.v. alhs; J. de VRIES, Altgermanische Religionsgeschichte (Grundriß d. germ. Philologie 12) I, Berlin 1956, S. 373; II, 1957, S. 251 u. 310; sowie R. SIMEK, Lexikon d. germ. Mythologie (Kröners Taschenausgb. 368), Stuttgart 1984, s.v. Heilige Haine. Die jüngeren Positionen bei A. GÜTTER, »Alladorf«, in: Arch. f.d. Gesch. Oberfrankens 78 (1998), z.T. im Anschluß an R. SCHMIDT-WIEGAND, Alach. Zur Bedeutung eines rechtstopographischen Begriffs der frankischen Zeit, bei DERS., Stammesrecht und Volksprache. Ausgewählte Aufsätze, Winheim 1991, S. 233-57 (aus Beitr. z. Namenforsch., N. F. 2, 1967, S. 21-45), die, ohne Alladorf selbst und die thüringischen Befunde aufzugreifen, auf höchst beachtlichem neuem Material fußt; dabei offenbleibende Fragen sind hier nicht zu diskutieren. Die Alladorfer Ausgrabungsergebnisse jetzt in weiterem Rahmen bei R. PÖLLATH, Karolingerzeitliche Gräberfelder in Nordostbayern. Eine archäologisch-historische Interpretation mit der Vorlage der Ausgrabungen von K. Schwarz in Weismain und Thurnau-Alladorf, 4 Bd., München 2002; vgl. bereits B. LEINTHALER, Der karolingisch-ottonische Ortsfriedhof Alladorf, in: Zschr. f. Archäologie d. Mittelalters 16/17 (1988/89), S. 7-122; H. LOSERT, Die früh- u. hochmittelalterl. Keramik in Oberfranken I (Zschr. f. Arch. d. Mittelalters, Beiheft 8), Köln-Bonn 1993, bes. S. 100 ff.; vgl. auch DERS. (wie Anm. 52) und J. HABERSTROH, Slawische Siedlung in Nordostbayern, bei A. Wieczorek - H.-M. Hinz (Hgg.), Europas Mitte um 1000, Stuttgart 2000, Bd. II, S. 713-717 (hilfreich auch zur Erfassung von Negativbefunden). Zu den rituellen Praktiken: O. RÖHRER-ERTL, Slawen - Deutsche. Beiträge zum ethnischen Wandel aus anthropolog. Sicht (Otnant-Gesellschaft, Quellen u. Erörterungen 2), Pressath 1999, bes. S. 85-102, passim, ergänzt durch DENS., Über Menschenreste aus dem karolingisch-ottonischen Reihengräberfeld von Alladorf, bei Pöllath II, S. 197-224. Ich hoffe, auf die von SCHMIDT-WIEGAND und durch die Ausgrabungsergebnisse aufgeworfenen Fragen in Kürze zurückzukommen. Herrn PD Dr. HANS LOSERT, Bamberg, der an den Grabungen in Alladorf persönlich beteiligt war, danke ich reiche Hinweise und intensive Diskussionsmöglichkeiten. 


\section{Kirche mit zweierlei Maß}

T wäre damit geographisch eingeordnet, und zugleich ist klar, wer sich hinter der ethnisch indifferenten Bezeichnung Sclaui verbirgt. Es sind diejenigen Glieder der weitausgreifenden Sprachfamilie, die die Forschung, fast wie nach Laune, teils nach dem Main, teils nach der Regnitz und ihrem Quellfluß, der Rednitz, benennt, weil eine zusammenfassende Selbstbezeichnung, falls sie jemals vorhanden war, nicht überliefert ist. Ihr Lebensraum war vor allem die sog. Fränkische Schweiz, eine Mittelgebirgsregion mäßiger Höhe mit den Eigentümlichkeiten der Juraformation, in der heute Orte wie Bamberg und Forchheim, Bayreuth, Kulmbach, Lichtenfels und Amberg tonangebend sind. Sprachlich tendierten sie, soweit Ortsnamen als fast einzige Überreste noch Anhalt bieten, teils zum Sorbischen, teils zum Tschechischen, was allerdings für die Zeit ihrer Einwanderung schwerlich schon spürbar war: Hier ist Einfluß sekundärer Sprachbewegungen anzunehmen, die nachträglich von verschiedenen Seiten her vordrangen und keine Rückschlüsse auf alte Einwanderungsrichtungen gestatten. Daß diese Slawengruppen ihre landschaftlich reizvolle Heimat jemals allein besessen haben könnten, ist unwahrscheinlich, und nichts spricht auch dafür, daß sie über eine sie alle zusammenfassende politische Organisation verfügt hätten, bevor die Franken kamen. Man hat zwar versucht, in dem Namen eines langezeit führenden Adelsgeschlechts jener Gegend, der Walpoten, so etwas wie eine slawische Würdebezeichnung wiederzufinden, doch das ist fehlgeschlagen ${ }^{52}$.

${ }^{52}$ Die einschlägige Forschung kommt nach längerem Pendeln zwischen »Slawophobie« und »Slawophilie« allmählich zu der Unbefangenheit, die in Mecklenburg, unter einem deutschen Fürstenhaus slawischer Abstammung, schon vor einem Jahrhundert selbstverständlich war (dazu auch nachstehend bei Anm. 53). Auszugehen ist von W. FRITZE, Untersuchungen zur frühslawischen und frühfränkischen Geschichte, Frankfurt/M. 1994, S. 36-44 m. Anm. 287-327 (S. 330-332). Die 1952 abgeschlossene Arbeit, durch besondere Umstände erst im angegebenen Jahr gedruckt, bringt eine kritische Auseinandersetzung mit dem Forschungsstand der Entstehungszeit, die durch die zunächst unterbliebene Publikation um ihre Wirkung kam. Inzwischen in Einzelheiten überholt, bringt sie noch immer gültige Beobachtungen zu sonst vernachlässigten Fragen. SCHWARZ (wie Anm. 11), bes S. 176-398, eine Pionierleistung, verschiedentlich angefeindet, bleibt materialreich und ist jedenfalls nicht ersetzt. NALEPA (wie Anm. 35) bedurfte der Ergänzung durch J. STRZELCZYK, Radanzwinidi, in SSS IV (1970), S. 446-448 (reiche Lit.), vgl. DENS., Problemy badań nad zachodnia peryferia osadnictwa słowianskiego w Niemzach, bei Dems (Hg.), Słowiańszczyzna Połabska między Niemcami a Polska, Poznań 1981, S. 187-189 (Forschungsbericht); auch DENS., Słowianie i Germanie w Niemczech środkowych we wczesnym średniowieczu, Poznań 1976, bes. S. 284 f. Weitere umfangreiche Nachweise bei ENDRES (wie Anm. 48), S. 161 f. m. Anm. 1-7; vgl. noch WALTHER (wie Anm. 31); R. KONRAD, Slawische Flurnamen in Oberfranken, in: Flurnamen-Kolloquium. Vorträge und Materialien, München 1988, S. 64-66 (leider nur Thesenpapier, aber wichtige weitere Lit.); H. LOSERT, Die slavische Besiedlung Nordostbayerns aus archäologischer Sicht, bei K. Schmotz (hg.), Vorträge 11. Niederbayerischer Archäologentag 1993, S. 207-270; DERS., Regnitzslaven, in: LMA VII (1995), Sp. 586 f.; HABERSTROH (wie Anm. 51); auch E. SZAMEIT, Merowingisch-slawischawarische Beziehungen im Spiegel archäologischer Bodenfunde des 8. Jh.s, in: Neues aus Alt-Villach. Jahrbuch des Museums der Stadt 31 (1994), S. 16 u. 18. Nicht mehr benutzt werden konnte der Austellungskatalog: Franken im Mittelalter, Stuttgart 2004. - Gewagte Thesen zu den Walpoten bei SCHÜTZ (wie Anm. 32), S. 161-168, dazu H.-D. KAHL, Der Staat der Karantanen (Supplement zu: R. Bratož - Hg. - , Slovenija in sosednje dežele med antiko in karolinško dobo - Slowenien und die Nachbarländer zwischen Antike und karolingischer Epoche I-II), Ljubljana 2002, S. 182-184, vgl. auch DENS., Die Kärntner Pfalzgrafschaft, in: Carinthia I/192 (2002), S. 211 Anm. 69. Slawische Abstammung des Geschlechts vermutete bereits E. HERRMANN (wie Anm. 48), S. 16-18; G. VOIT, Die Walpoten (Die Fränkische Schweiz - Heimatkundliche Beihefte 11), Erlangen und Jena 1996, S. 12, vgl. 7, rechnet mit ursprünglichen Franken aus dem burgundischen Zweig eines weiter verbreiteten Geschlechts, nimmt aber weder die Gesichtspunkte von E. HERRMANN zur Kenntnis noch die von SCHÜTZ, S. 163 u. 168 aufgeworfene Frage nach der ursprünglichen verfassungsgeschichtlichen Stellung des Wal(t)poten-Amtes, dessen Titel die Familie als Eigennamen weiterführte. 
Nicht zu vergessen ist, daß diese zweifellos niemals besonders starke Bevölkerungsgruppe nichtgermanischer Sprache zu den Vorfahren des einheitlich deutschsprachigen Frankentums gehört, das sich seit dem Mittelalter in diesen Gegenden entwickelt hat. Sie bilden daher ein gemeinsames Anliegen der slawischen Altertumskunde und der deutschen Volksgescichte ${ }^{53}$.

Für eine derart schlecht beleuchtete Bevölkerungsgruppe eine zusätzliche Quelle gesichert zu haben, kann nur willkommen sein. Doch nochmals: wie sollen wir sie - wie sollen wir T benennen? DOVE, dessen Zuweisung damit gegen die jüngeren Vorschläge recht behält, sprach vom »Sendrecht der Main- und Rednitzwenden«. Das hat gleich zwei Schönheitsfehler. Sie ergeben sich, wenn man diesen Vorschlag dem Einleitungssatz gegenüberstellt: Statutum est qualiter Sclaui uel ceterae nationes, que nec pacto nec lege Salica utuntur, ... constringendi sint... - »Es ist festgesetzt worden, wie die Slawen (oder: Wenden) und die übrigen Bevölkerungsgruppen, die weder den pactus noch die lex Salica anwenden, ... in Zaum zu halten sind«. Da ist sehr wohl von Slawen oder Wenden die Rede, doch nicht allein von ihnen, nur daß andere, immerhin nationes genannt, neben ihnen nicht mit einem Zahlenanteil hervortreten, daß es lohnte, auch sie namentlich herauszustellen. Es handelt sich also um eine Satzung, die Slawen und Nichtslawen im Bezugsgebiet gemeinsam erfaßt, das aber, wohlgemerkt, als Sonderregelung, von der andere ausdrücklich ausgenommen sind. Diese Ausnahmen werden nicht ethnisch definiert, sondern nach Rechtsfamilien, was doch wohl auf die übrigen Glieder der Aufzählung zurückwirkt - Gegebenheiten weltlichen Rechts, das in Sachen kirchlicher, geistlicher Disziplin eigentlich nichts zu suchen hat.

Das ist ungewöhnlich. Paßt aber dafür die Bezeichnung »Sendrecht«? Ein solches müßte doch wohl für sämtliche Gemeindeglieder des Sprengels gelten, den ein Sendgericht jeweils zu erfassen hat, ohne Ansehen der Person. Offenbar stoßen wir hier auf Verhältnisse, die uns ferngerückt sind und sich mit geläufiger Begriffssystematik nicht ohne weiteres erfassen lassen. Dazu genügt es auch nicht, wie einige Autoren, für "Sendrecht« ein »Sendweistum« einzusetzen ${ }^{54}$. Ein Weistum ist zwar fähig, Sonderverhältnisse abzudecken, aber es wird nicht »beschlossen« (statutum est), es wird gefunden und verkündet. Das paßt für eine so offenbare Synodalentscheidung schlecht. Wir müssen eingehender analysieren.

Unter nationes wird man, gerade in der Gegenüberstellung mit Sclaui, zunächst Gruppierungen ethnischer Art verstehen. Die frühmittelalterliche Bevölkerungsgeschichte des Obermaingebietes zeichnet sich nicht durch besondere Durchsichtigkeit aus. Mit ziemlicher Bestimmtheit dürfen wir jedoch für die Würzburger Diözese vor der Abzweigung Bambergs mit Splittern der eben erwähnten Thüringer rechnen. Alemannen und etwaige Sprachverwandte müssen im heutigen Unterfranken die Bevölkerungsmehrheit

${ }^{53}$ Diese z. T. vielleicht noch ungewohnte Sicht ist Konsequenz der modernen Ethnogeneseforschung. Bahnbrechend: R. WENSKUS, Stammesbildung und Verfassung, Köln-Graz 1961 = Köln-Wien 1977 (vgl. bes. im Register unter »Wandel der ethnischen Selbstzuordnung«). Weiteres bei KAHL, Karantanen, bes. S. 449-452 m. Anm. 954, auch S. 30 u.ö. Zur Einfügung ursprünglich slawischer Elemente in die deutsche Volksgeschichte: DERS., Zum Geist der deutschen Slawenmission des Hochmittelalters, bei Beumann (wie Anm. 74), S. 156 f. m. Anm. 4 (aus Zschr. f. Ostforsch. 2, 1953, S. 1 f.), sowie die Diskussionsbemerkung von DEMS. bei E. Birke - E. Lemberg (Hgg.), Geschichtsbewußtsein in Ostmitteleuropa, Marburg/Lahn 1961, S. 78-80 (in weiterem Rahmen wiederholt in Carinthia I/186, 1996, S. 423 ff.). Zur Assimilierung der Mainslawen bes. E. HERRMANN (wie Anm. 27).

${ }^{54}$ E. MAYER (wie Anm. 30); O. MAYER (wie Anm. 43), S. 180; E. HERRMANN (wie Anm. 27), S. 174. 
gestellt haben, so daß sie die sprachliche Zukunft des Landes zu bestimmen vermochten. Im Obermaingebiet zeigen Ortsnamenbildungen mit Schwab-, daß gleichartige Bewohner sich von denen der Umgebung abhoben: Es waren Streusiedlungen in einem ethnischen Mischgebiet. Auch Sachsen sind zu bemerken, die unter Karl d.Gr, zwangsumgesiedelt worden waren, um ihren Widerstand gegen die Christianisierung zu brechen (der Gedanke an sie mag besonders nahe liegen, weil auch die Capitulatio de partibus Saxoniae ausdrücklich gegen Bestattungen in oder bei den tumulus - sic! paganorum vorgeht, doch sind Hügelgräber ebenso von anderen Germanen bekannt und auch von Slawen). Nicht zu vergessen sind Baiern, die schon in vorkarolingischer Zeit auf ostfränkischem Boden aktiv werden konnten, doch wohl später nochmals am Landesausbau mitgewirkt haben. Franken waren imstande, dem Lande auf Dauer den Namen zu geben wie die Normannen in der Normandie, müssen aber wie diese so weitgehend in zahlenmäßiger Minderheit geblieben sein, daß ihre völlige sprachliche Assimilierung möglich wurde ${ }^{55}$.

Man sieht: Das sind durchweg Teile alter Völkerschaften, für die - im Gegensatz zu den Slawen gleicher Zeit - Aufzeichnungen überlieferten Rechts bekannt sind, sog. leges barbarorum. Allerdings griff der Sinngehalt von natio im damaligen Latein weiter: Der Ausdruck konnte auch für Geburtsstände eintreten, die ihrerseits die individuelle Rechtsstellung bestimmten, wie ingenui und servientes ${ }^{56}$. Wer T entwarf, hatte in weitem Umfang auch mit Unfreien zu rechnen - den coloni fiscalini, die an anderer Stelle angesprochen werden, oder den Hintersassen jener domini privater predia, von denen später gleichfalls die Rede ist. Bevölkerungsschichten wie diese dürften weitgehend abseits der leges gestanden haben - nicht zuletzt die Nachkommen von Zwangsumsiedlern, deren angestammte Rechte jedenfalls einem Gefangenenstatus zum Opfer gefallen waren. Wo sendgerichtliche Fragen zu regeln waren, galt es Sorge zu tragen, daß alle erfaßt wurden, die nicht ausdrücklich ausgeklammert bleiben sollten. Wir müssen damit rechnen, daß T mit nationes als Oberbegriff auch die Unfreiheit als »Recht, in das man hineingeboren ist«, einbezogen hat.

Der Blick richtet sich auf die Ausnahmen, die in T festgeschrieben sind. Im Umkehrschluß sind das diejenigen, die sich entweder an den pactus halten oder an die lex Salica. Allerdings geraten wir damit an eine Formel, die nicht eben leicht aufgeknackt werden kann.

Einigermaßen klar ist nur ihr zweites Glied: Es kann nichts anderes meinen als eine wie immer geartete Form desjenigen Rechts, von dem unter diesem Titel verschiedene

${ }^{55}$ Zusammenfassend: LUBICH (wie Anm. 41), S. 17 m. Anm. 8-12, vgl. S. 33, 35 u. 51; vgl. H. WEIGEL, Ostfranken im frühen Mittelalter, in: Bl.f.dtsch. Landesgesch. 95 (1959), S. 204-206, sowie K. LINDNER, Unters. z. Frühgesch.d.Bistums Würzburg (Veröff.d.Max-Planck-Inst. f. Gesch. 35), Göttingen 1972, S. 38-41; KAHL (wie Anm. 28), S. 74 f. Sachsensiedlungen können teilweise hochmittelalterlich sein, karolingerzeitlicher Grundstock ist m.E. nicht zu bezweifeln, Diskussion würde hier abführen; tumuli oben Anm. 19. - Zu den Baiern einerseits W. STÖRMER, Bayerisch-ostfränkische Beziehungen vom 7. bis zum frühen 9. Jh., bei H. Wolfram - A. Schwarcz (Hgg.), Die Bayern und ihre Nachbarn I (Denkschr. d. Österr. Akademie d. Wiss., phil.-hist. Kl. 179), Wien 1985, S. 227-252, andererseits E. SCHWARZ, Zum Problem der wendischen Flurnamen am oberen Main, in: Berichte d.Hist. Vereins Bamberg 99 (1963), S. 456. - Frankensiedlung: WENSKUS (wie Anm. 53), S. 540 f. m. Lit. auch zu den sprachgeschichtlichen Problemen, zu denen nochmals Arbeiten von E. SCHWARZ hervorzuheben sind, dazu W. SCHLESINGER, Zur politischen Geschichte der fränkischen Ostbewegung vor Karl d.Gr., bei H. Patze - F. Schwind (Hgg.), Ausgewählte Aufsätze von Walter Schlesinger 1965-1979 (Vorträge und Forschungen 34), Sigmaringen 1987, S. 1-48, passim (Wiederabdruck aus: W. Schlesinger - Hg. - , Nationes II, Sigmaringen 1975, S. 9-61), sowie DENS., wie Anm. 60, passim.

${ }^{56}$ KAHL (wie Anm. 29), S. 67 f. 
Versionen aufgezeichnet worden sind - ob es für diesen Fall ebenso schriftlich oder nur gewohnheitsmäßig fixiert zu denken ist, muß offen bleiben. In jedem Fall ist es ein fränkisches Recht im älteren Sinn, der noch nicht auf die Landschaften am Main bezogen war; ein Recht allerdings, das, wenn wir eine alte Formel richtig verstehen, mindestens zeitweise auch auf Nichtfranken übertragen werden konnte ${ }^{57}$. Ob und wie weit das noch im karolingerzeitlichen Umland dieses Flusses geschah, entzieht sich dem Einblick. War es der Fall, so könnte dies eine wesentliche Brücke gewesen sein, den alten Namen auf die Träger nichtfränkischer Mundarten in dieser Region umzuleiten.

Probleme macht der pactus, der hier an erster Stelle steht, also für das Bezugsgebiet damals die höhere Relevanz besaß. Der Ausdruck erscheint quellenmäßig in einer Weise, die sich bestimmter Systematisierung entzieht, oft in Verbindung mit lex, oft isoliert oder in anderem Zusammenhang ${ }^{58}$. Er kann sich auch mit lex Salica verbinden. Diese Möglichkeit scheidet für T jedoch aus: Die nec - nec - Konstruktion vollzieht eine unmißverständliche Gegenüberstellung. Im übrigen tritt pactus für drei andere leges auf: die ripuarische, die alemannische und die baierische ${ }^{59}$. Es trifft sich, daß, wie eine lex Salica, so auch diese drei sämtlich in mainfränkischer Überlieferung vorliegen, aus alten Beständen der Dombibliotheken von Würzburg und Bamberg ${ }^{60}$. Der starke Anteil des jüngeren Bistums an diesen Beständen ist besonders beachtlich, denn er beweist die Fortdauer entsprechenden Informationsbedarfs noch für Zeiten, in denen T längst fixiert war. Doch wie sollen wir über einen solchen Befund zu einer Lösung kommen - wie herausfinden, was nun sich hinter seinem pactus verbirgt?

Für die alemannische wie für die salische Lex lassen sich Gründe nennen, warum es sich nicht empfiehlt, hier zuerst an sie zu denken. Erheblich genug, um beide mit

${ }^{57}$ R. SCHMIDT-WIEGAND, Franken und Alemannen. Zum Gebrauch der Stammesbezeichnungen in den leges barbarorum, bei DERS., Stammesrecht (wie Anm. 51), S. 435-437 (aus: G. Althoff u.a. - Hgg. - , Person und Gemeinschaft im Mittelalter. Fschr. Karl Schmid, Sigmaringen 1988); FRITZE (wie Anm. 52), S. 257 m. Anm. 1590 (S. 419); vgl. KAHL (wie Anm. 28), S. 75 m. Anm. 31, sowie A. WIECZOREK, Identität und Integration. Bevölkerungspolitik der Merowinger usw., in: Die Franken - Wegbereiter Europas - Ausstellungskatalog Mannheim, Mainz 1997, Bd. II, S. 346-357.

${ }^{58}$ Übersicht vermittelt R. BUCHNER, Die Rechtsquellen. Beiheft zu Wattenbach-Levison, Deutschlands Geschichtsquellen im Mittelalter, Weimar 1953, Register S. 85 f., s.vv. lex bzw. pactus, dazu die Bemerkungen bes. S. 30 Anm. 126, vgl. S. 22 Am., 82 u.ö. Nicht erfaßt sind dort Belege für pactus abseits von Titulierungen, in bloßen Bezugnahmen auf Rechtsquellen, z.B. in Zitaten wie unten Anm. 61.

${ }^{59}$ SCHMIDT-WIEGAND ebd., S. 434, Anm. 53, dazu E. LAUFMANN, Pactus, pactum, in: Handwörterbuch zur deutschen Rechtsgesch. III (1984), Sp. 1403-1405, bes. 1404.

${ }^{60}$ Die Bamberger Dombibliothek besaß einen Kodex, der die Lex Salica emendata, die Lex Ribuaria (Kl. B) und die Lex Alamannorum (Kl. B) mit anderem Material kombiniert, die letzte durch Blattverlust unvollständig (jetzt Bamberg, Staatsbibliothek, Jur. 35, älter D.33 und II/2), vgl. MORDEK (wie Anm. 17), S. 17-19. Die Lex Alamann. (Kl. B) sowie den Prolog der Lex Baiuv. hat München, Bayer. Staatsbibl., Lat. 4460 (aus dem Dominikanerkloster Bamberg), vgl. MORDEK, ebd., S. 309 f. - Die Lex Baiuv. hat Bamberg, Staatsbibl., Can. 7 (aus Dombibliothek), vgl. MORDEK, ebd., S. 11. Auf fragmentarische Überlieferungen verweist E.Frh.v. SCHWIND zur Ausgabe MGH Leg.Nat.Germ. V/2 (1926), S. 182 u. 188 (Provenienz Würzburg bzw. Amorbach und Bamberg). - Zur Lex Salica ist zu bemerken, daß die entsprechende Lesart für T gegen die Eichstätter Überlieferung bereits unwiderleglich durch DOVE 1864 (wie Anm. 26), S. 160, Anm. 10, sichergestellt wurde. Außer der oben vermerkten besaß Würzburg, Dombibliothek, eine weitere Lex Salica emendata, kombiniert mit zahlreichen Kapitularien, jetzt Codex Dent V App. 96 der Nürnberger Stadtbibliothek (MORDEK, ebd., S. 401-404). Auch hier sind Fragmente (Einzelblätter, z. B. aus Kloster Michelsberg) nachgewiesen. - Keine mainfränkische Überlieferung existiert für Lex Thuringorum und Lex Saxonum, die beide überhaupt nur selten erscheinen. - Vgl. auch H. LIERMANN, Zur mittelalterl. Rechtsgesch. Frankens, in: JFLF 5 (1939), bes. S. 16, dazu 7 u. 15, in Verbingund mit G. THEUERKAUF, Buchard von Worms und die Rechtskunde seiner Zeit, in: Frühmittelalterl. Studien 2 (1968), S. 156-160 m. Anm. 56-58. 
Sicherheit auszuscheiden, sind sie allerdings nicht ${ }^{61}$. Das muß festgehalten werden. Andererseits kann zu ihren Gunsten nichts angeführt werden als der bloße Umstand, daß die beiden entsprechenden Bevölkerungselemente im Bezugsgebiet vorhanden waren. Weder für den einen noch für den anderen dieser pacti sind Motive ersichtlich, die gerade ihm eine Vorzugsstellung noch vor der Lex Salica hätten verschaffen können - Zahlenverhältnisse kennen wir ja nicht.

Das alles ist bei der Lex Ribuaria anders. Gegen sie spricht nichts, aber beachtlich viel Positives fällt in gerade ihre Waagschale. Diese Lex war wie die Salica ein fränkisches Recht im ursprünglichen Sinn des Begriffs, ein jüngerer Sproß aus gleichem Stamm. Die Franken waren das »Reichsvolk $^{62}$ im karolingischen Imperium und blieben es in seinem ostfränkischen Nachfolgestaat für eine geraume Übergangszeit: Noch der nachmalige Kaiser Heinrich II. betonte bei seinem Herrschaftsantritt als König in der Siegellegende die Renovatio Regni Francorum und hat damit ganze Historikergenerationen mit Diskussionsstoff versorgt ${ }^{63}$. Ein Unterschied in der Wertung des ribuarischen Rechts vor dem salischen, was den Rang angeht, ist nicht wahrnehmbar, auch wenn für uns die Schriftform des ersten die ältere bleibt. Das eine vor dem anderen zu nennen, war unverfänglich, wenn etwa die Bevölkerungsmischung des Bezugsgebietes ihm ein Übergewicht an praktischer Bedeutung verlieh. Daß das Kolonialgebiet am Main - denn ein solches war es - dem Frankenreich stärker von »Ribuariern« als von »Saliern« erschlossen worden sein wird, kann zwar nur hypothetisch angenommen werden, doch hat es keinerlei Wahrscheinlichkeit gegen sich.

Hinzu kommt ein Zweites. Der Tenor von T richtet sich gegen gesteigerte Mängel an christlicher Glaubenstreue, kirchliche Disziplin eingeschlossen, die für das Zeitempfinden untrennbar zu ihr gehörte. Das Christsein, verknüpft mit dem Bewußtsein von Auserwähltheit und Sendung, war ein Grundelement im Selbstverständnis der Franken - der Franken als solchen, ohne Beschränkung auf die eine oder andere ihrer Rechtsfamilien $^{64}$; es war möglich, sie auf gleicher Ebene mit Byzantinern und Römern

${ }^{61}$ Im Titel einer Lex Alamannorum erscheint pactus nur in einer von über 50 Handschriften, und das in einer westfränkischen Überlieferung (Abtei St-Lomer zu Blois), vgl. MORDEK, S. 584, sowie C. SCHOTT, LMA V (1991), Sp. 1927 s.v. Die Lex Baiuvariorum ist im erhaltenen mainfränkischen Bestand verhältnismäßig jung (Codex 11. Jh.); ihr Erwerb durch eine Dominikanerbibliothek kann mit Bedürfnissen zusammenhängen, die erst durch hochmittelalterlichen Landesausbau entstanden, wie ihn SCHWARZ (oben Anm. 55) erwähnt. Pactus erscheint für sie in keiner Handschrift im Titel, kommt nur in wenigen Bezugnahmen anderer Texte aus der Zeit vor dem Sturz Tassilos III. auf altbaierischem Boden vor, vgl. Conc. Ascheimense, c. 4, und Dingolfingense, c. 9. (MGH Conc. II/1, 1906, S. 57, 17 f., bzw. 95, 12).

${ }^{62}$ Diesen Terminus finde ich zuerst bei G. TELLENBACH, Die Entstehung des Deutschen Reiches, München 1940, S. 44, dazu S. 43-53, vgl. 3. Aufl., o.J. (1947), S. 47, dazu S. 45-59; ergänzend vor allem W. SCHLESINGER, Die Franken im Gebiet östlich des mittleren Rheins, bei F. Petri (Hg.), Siedlung, Sprache und Bevölkerungsstruktur im Frankenreich (Wege der Forschung 49), Darmstadt 1973 (Wiederabdruck aus Hessisches Jahrbuch für Landesgeschichte 15, 1965, S. 1-22).

${ }^{63}$ Dazu jetzt B. SCHNEIDMÜLLER - St. WEINFURTER (Hgg.), Otto III. - Heinrich II.: Eine Wende? (Mittelalter-Forschungen 1), Stuttgart 2000, mit zahlreichen Einzelbeiträgen.

${ }^{64}$ Oft behandelt, z.B. G. TELLENBACH, Römischer und christlicher Reichsgedanke in der Liturgie des frühen Mittelalters, in: Sitzungsberichte der Akademie d.Wiss. Heidelberg, phil.-hist. Kl. 1934/1, S. 20 ff.; E. DELARUELLE, Essai sur la formation de l'idée de Croisade I.: La guerre sainte sous Charlemagne, in: Bulletin de Litterature ecclésiastique 42 (1941), S. 25-45, passim (Neudruck bei DEMS., L’idée de croisade au moyen âge, Torino 1980, S. 3-23); W BAETKE, Die Aufnahme des Christentums durch die Germanen, Darmstadt 1959, S. 45-53 (Neudruck aus: Die Welt als Geschichte 9, 1943); E. RIEBER, Die Bedeutung alttestamentlicher Vorstellungen für das Herrscherbild Karls d.Gr. und seines Hofkreises, Diss./Ms. Tübingen 1949, passim, bes. S. 203; E. ZÖLLNER, Die politische Stellung der Völker im Frankenreich (Veröff.d. Inst. f. Österr. 
vor anderen als religiöses Vorbild aufzubauen ${ }^{65}$. Selbstverständlich war nicht auszuschließen, daß in der Realisierung auch unter ihnen immer wieder Rückstände blieben, nicht einmal solche von erheblicherem Gewicht. Doch T rechnet nicht allein mit Mängeln, es nimmt Widerstände gegen kirchliche Korrekturbemühungen aufs Korn, Widerstände von derart massivem Schlag, daß sie nur mit drastischsten Mitteln zu brechen waren bis hin zu Güterkonfiskation und Friedloslegung; selbst Sabotage kirchlicher Gegenmaßnahmen schien möglich - sie war so weit in Rechnung zu stellen, daß sie nicht allein als seltene Ausnahme in Betracht kam. Das liegt nicht in der Richtung dessen, was man Franken der mutmaßlichen Entstehungszeit - der ersten Hälfte des 10. Jahrhunderts - ohne weiteres zutrauen möchte. Verstärktes Gewicht aber gewinnt es, wenn man es im Licht einer seltsamen Formel betrachtet, die der besonderen Religiosität fränkisch-karolingischer Prägung entsprang. In geistreichem Spiel mit vorgefundenen Bedeutungsnuancen der lateinischen Schriftsprache kam sie zu einer Wendung, die für uns unübersetzbar bleibt, der Formel vom fidelis Dei et regis - von dem, der den Glauben an Gott und die Treue zum Herrscher als unverbrüchliche Einheit bewahrte - , und auch sie überdauerte die Karolingerzeit des Reiches beträchtlich ${ }^{66}$. Abwendung vom einen war demnach gleichbedeutend mit Abfall vom anderen, und beides berührte in gleicher Weise die Herrschaft des »Reichsvolks«, dessen Repräsentanz, beilaufig, unter den Verhältnissen des Koloniallandes nicht unvorsichtig geschwächt werden durfte.

Niemand wird bestreiten wollen, daß Vorstellungen dieser Art auch an der fränkischen Durchdringung der Mainlande beteiligt gewesen sein müssen. Neben dem Entfallen sonstiger Schwierigkeiten, wie sie sich hier für eine etwaige Vorzugsstellung von alemannischer und baierischer Lex melden, gibt das verstärkte Ermutigung, den pactus in T als Ribuarierrecht zu deuten. Qui et pacto et lege Salica utuntur (um den Ausdruck der Quelle positiv zu wenden), wäre dann zusammenfassende Bezeichnung für die Vertreter des fränkisch-christlichen Reichvolks, eingeschlossen (sofern es sie im Bezugsgebiet gab) Nichtfranken im ethnischen Sinn, denen der Anschluß an eine der fränkischen Rechtsfamilien geglückt war, und deren Nachkommen. Daß sie gleichfalls Kirchenglieder waren, kann nicht bezweifelt werden. Auch sie müssen folglich beim Sendgericht zugegen gewesen sein. Offenbar aber wurden für sie sendrechtliche Regelungen gewöhnlicher Art mit normalen Kirchenbußen für ausreichend gehalten - Sondermaßnahmen, wie T sie zusammenstellt, schienen notwendig nur für die "anderen", für Slawen, für Thüringer, für Alemannen, Baiern, Sachsen und etwaige weitere nationes im oberfränkischen Mischgebiet.

Dabei ist nicht aus dem Blick zu verlieren, daß die Repräsentanten fränkischen Rechts ohne jeden Zweifel zugleich diejenigen waren, denen die Grafen und sonstigen

Geschichtsforsch. 13), Wien 1950, bes. S. 40, 67-70 u. 72 f.; H. KÄMPF, Reich und Mission zur Zeit Karls d.Gr., in: Geschichte in Wissenschaft und Unterricht 1 (1950), S. 412 ff.; HELBIG (wie Anm. 66), bes. S. 284.; R. SCHMIDT-WIEGAND, Gens Francorum inclita. Zu Gestalt und Inhalt des längeren Prologs der Lex Salica, in: Festschr. A. Hofmeister, Halle/S. 1955, bes. S. 246.

${ }^{65}$ Vgl.z.B. das sog. Concilium Bavaricum, c. 6 (MGH Conc. II/1, S. 52,32; auch lat.-dtsch. bei R. Rau - Hg. - , Briefe des Bonifatius usw., = Ausgew. Quellen z. deutschen Gesch.d.Mittelalters IV b, Darmstadt 1968, Anhang, S. 442, 5f.) über das religiöse Vorbild der Greci et Romani seu et Franci. Neuerdings auf die Zeit um 800 datiert (W. HARTMANN, Die Synoden der Karolingerzeit im Frankenreich und in Italien, Paderborn usw. 1989, S. 90 sowie 144 Anm. 12). Im Hinblick auf die Auseinandersetzungen im Zusammenhang mit der Frankfurter Synode von 794 wird an einen gewissen Abstand zu diesem Ereigniszusammenhang gedacht werden müssen.

${ }^{66}$ H. HELBIG, Fideles Dei et regis. Zur Bedeutungsentwicklung von Glaube und Treue im hohen Mittelalter., in: Arch. f. Kulturgesch. 33 (1951), bes. S. 283-291. 
Herrschaftsträger im Lande entnommen wurden, mindestens mehrheitlich. Die Art, wie sie in $\mathrm{T}$ in das Exekutionsverfahren gegen hartnäckige Pönitenzverweigerer eingeschaltet werden, ist der Forschung längst aufgefallen; mehrfach hat sie zu der Frage geführt, ob nicht, um diesem Text Rechtskraft zu verleihen, eine Mitwirkung des Herrschers unerläßlich war ${ }^{67}$, obwohl bisher keinerlei Anhalt aufgespürt werden konnte, wie diese Mitwirkung erfolgt sein könnte ${ }^{68}$. Die Kirche amtiert im Rahmen und im Dienst des ostfränkischen Reiches, als Herrschaftsinstrument, ohne ihre Aufgaben darin zu erschöpfen; sie tut dies im engsten Zusammenwirken mit den Trägern weltlicher Gewalt, und Christlichkeit, genauer: Kirchlichkeit im von oben her gewünschten Sinne, wird zum Loyalitätsbeweis (nahe der Grenze zum immer noch unruhigen Böhmen mag dies besonders wichtig geworden sein). Eben deshalb aber werden Kategorien weltlichen Rechts fähig, die Gleichheit aller Christen vor Gott zu durchkreuzen. Wesentliche Rätsel des Textes lösen sich, wenn der pactus in T als Führer zu den Grundstrukturen des fränkischen Reichsvolks verstanden wird, des Volks der fideles Dei et regis schlechthin, das andere überschichtet.

T entpuppt sich damit als eine Quelle, die den Imperialismus dieses Reichsvolks mit einer Deutlichkeit repräsentiert wie vielleicht keine zweite. Sie bleibt in der praktischen Anwendung dem Sendgericht verhaftet, doch allein darum ist sie, wie gesagt, nicht gleich auch ein »Sendrecht«. Was sie bietet, ist kirchliches Sonderrecht für Nichtfranken, verstanden im Rechtssinn, von Franken einsentzbar, um jene zu disziplinieren. Man mag etwa vom Würzburger Sondersendrecht für Nichtfranken sprechen, auch wenn dies vielleicht etwas umständlich scheint. Vereinfachung dient nicht immer der Klarheit.

Damit ist der problematische Text nicht nur geographisch, sondern auch inhaltlich eingeordnet, und wir sind frei, uns endlich der Frage zuzuwenden, was ihm über das einstige Slawentum Oberfrankens und seine religiöse Situation im frühen zehnten Jahrhundert entlockt werden kann.

${ }^{67}$ G. WAITZ, Deutsche Verfassungsgeschichte IV, Berlin 1861, S. 439 Anm. 6 (nicht mehr an entsprechender Stelle der jüngeren Auflagen); DOVE 1864 (wie Anm. 26), S. 171 f. Anm. 44; RIEZLER (wie Anm. 27), S. 397 f.; Rich. SCHRÖDER, Die Ausbreitung der salischen Franken, in: Forsch. z. deutschen Gesch. 19 (1879), S. 140; P. HINSCHIUS, Das Kirchenrecht der Katholiken und Protestanten IV/1, Berlin 1886, S. 292 m.Anm. 7; allgemein über derartige Bestätigungen im Frankenreich: K. VOIGT, Staat und Kirche von Konstantin d.Gr. bis zum Ende der Karolingerzeit, Stuttgart 1936, S. 266 f. u. 398, vgl. 401.

${ }^{68} \mathrm{Zu}$ denken ist evtl. an Besiegelung einer Würzburger Ausfertigung durch die königliche Kanzlei bei einer zweit- oder drittrangigen Gelegenheit, bei der der Erzbischof von Mainz nicht beteiligt war: Der Text gelangte offensichtlich nicht in Mainzer Überlieferung, obwohl die Erzdiözese ihn in ihrem ostthüringischen Eigenbereich gut hätte nutzen können (vgl. O. DOBENECKER, Regesta diplomatica necnon epistolaria historiae Thuringiae I, Jena 1895, S. 191 f., Nr. 911-912, dazu H. LEO, Untersuchungen zur Besiedelungs- und Wirtschaftsgeschichte des thüringischen Osterlandes, Leipzig 1900, S. 62-66, sowie SCHWARZ - wie Anm. 11 - , S. 362); im übrigen wäre der Text über Mainz bestimmt in die Sammlungen Burkhards gelangt. Andererseits stimmt er so stark zum Geist der Synoden von Tribur 895 und Hohenaltheim 916, daß man sich ungern weit von ihnen entfernen möchte, ganz abgesehen vom gespiegelten Entwicklungsstand des Sendgerichtswesens, der hier nicht auszubreiten ist. Königsaufenthalte in Würzburg selbst sind nach erhaltenen Herrscherurkunden (vgl. die Register zu MGH DD) zwischen 793 und 915 nicht bezeugt; mit 918 bricht die Reihe für in Betracht kommende Zeit ab. Bischof Thiedo mußte sich 923 nach Quedlinburg begeben, um seine Privilegien erneuern zu lassen. 941 genügte eine Reise nach Salz, wo von 927-948 sechs Königsaufenthalte nachweisbar sind. Weitere in relativer Nähe zu Würzburg sind für Forchheim und für Rohr gesichert; 907 weilte Ludwig IV. wohl in Furt a. Regnitz - Bischof Rudolf erscheint dort als Intervenient. Damit ist der Kreis möglicher Gelegenheiten wohl ungefähr abgesteckt. An Vollständigkeit der erhaltenen Zeugnisse glaubt niemand. 


\section{Eigenes Recht im fränkischen Untertanenverband}

Ein Synodalbeschluß ist eine Satzung rechtlicher Art. Sie schreibt Normen fest, die erreicht oder bewahrt werden sollen, doch keinerlei Hinweis vermag sie zu bieten, was jemals zu deren Realisierung geschah und wie weit es dabei im Sinn der Urheber Erfolge gab oder Mißerfolge. Vielleicht beleuchtet sie über die festgeschriebenen Normen hinaus andere rechtliche Ordnungen, z.B. das Herrschafts- und das Sozialsystem. Allgemeine Lebensumstände bleiben außerhalb des Lichtkegels; Auskunft über Siedlungsverhältnisse, Nahrungsbeschaffung, Kleidung und Ausrüstung, um nur dies anzuführen, ist nicht zu erwarten. Geistige Welten abseits dessen, was sich rechtlich normieren läßt, werden höchstens einmal andeutungsweise gestreift, wo sie diesen Umkreis berühren.

Das Würzburger Sondersendrecht für Nichtfranken zeigt uns Slawen als ein Bevölkerungselement unter anderen. Ihr Anteil an der Gesamtzahl hebt sie über diese anderen hinaus, offenbar wesentlich. Rechtlich jedoch, und das verdient Hervorhebung, erscheinen sie den übrigen gleichgestellt, ausgenommen allein die Repräsentanten des Reichsvolks. Diese sind es, denen im Rahmen des Ganzen eine Sonderstellung zukommt, ausgezeichnet durch bevorzugte Privilegierung. Slawen und sonstige rücken ihnen gegenüber in eine gemeinsame Kategorie. Sprachverwandtschaft mit dem Reichsvolk spielt dafür keine Rolle.

Eine völlig homogene Masse von Reichsuntertanen entsteht allerdings durch diese Grundgegebenheiten nicht. Die Bevölkerung gliedert sich in nationes, unter die die Slawen sich einreihen, als stärkste und daher als einzige besonders hervorhebenswert. Der Textzusammenhang legt nahe, diese nationes als Rechtsgemeinschaften zu verstehen, die durch Abstammung, durch Geburt konstituiert sind; ob und wie weit Zugehörigkeit auch unabhängig von ethnischen Unterschieden erworben oder verliehen werde konnte, bleibt unbeleuchtet. Daß Rechtsgemeinschaften angesprochen sind, zeigt schon die Art, wie die beteiligten Franken eingeführt werden, ohne Volksnamen, allein durch Hinweis auf zwei ihrer Rechte. Bestätigt wird es durch die Festsetzung, Anklage vor dem Sendgericht dürfe erhoben werden ohne Rücksicht auf ethnische Abstammug, Rechtsstand und Sprache (cuiuscumque sit gentis, nationis uel linguae), und zwar von Anklägern ebenfalls beliebiger Rechtszugehörigkeit und Sprache (cuiuscunque nationis uel linguae), unter ausdrücklichem Ausschluß des Einspruchs, der Ankläger gehöre einer anderen Rechtsgemeinschaft und Volksgruppe an als der Beklagte (penitus quia unius legis et gentis non sunt obiectione remota). Lex kann hier unmöglich, wie häufig, auf Religionszugehörigkeit zielen, denn auch die Beklagten sind getauft, durch das Taufgelübde gebunden - dazu wird sogleich noch mehr zu sagen sein. Es muß sich folglich um eine Lex im Sinn des karolingerzeitlich-weltlichen Personalitätsprinzips handeln, wie sie z. B. für Alemannen, Baiern und Thüringer in förmlicher Aufzeichnung vorliegen. Der ausdrückliche Ausschluß des genannten Anfechtungsgrundes aber hat Sinn nur, wenn die Zeit und Gegend ihn sonst im Gerichtsverfahren zuließ. Man denkt an ein Rechtsbuch, das 300 Jahre jünger ist als dieses Sondersendrecht und aufgezeichnet in einer Region mit sehr viel einfacheren Bevölkerungsverhältnissen, nämlich an den Sachsenspiegel, der im ostfälischen Umfeld seiner Entstehung nur mit zwei Nationalitäten zu rechnen hatte, mit Sachsen und mit »Wenden«. Dort ist festgehalten, daß Sachsen und Wenden nicht gegen einander Urteil finden dürften, wobei offenbar das Leisten von Zeugenschaft eingeschlossen zu denken ist. Nur zwei Ausnahmen bleiben offen: Wo unter Königsbann 
gerichtet wird, also in Grafschaften älterer Form, und im Fall daß jemand auf handhafter Tat ergriffen wird ${ }^{69}$. Die Würzburger Satzung und die jüngere Regelung Ostfalens weisen unverkennbar auf eine gemeinsame Wurzel, die hier aus dem Spiel bleiben muß ${ }^{70}$. Dabei ist bemerkenswert, daß das geistliche Sendgericht für sich dieselbe Stellung beansprucht wie das Grafengericht, das in Stellvertretung des Herrschers amtiert. Einmal mehr zeigt sich das Gewicht der Formel vom fidelis Dei et regis.

Dürfen die Slawen am Obermain, an Rednitz und Regnitz als Rechtsgemeinschaft aufgefaßt werden? Waren sie - oder doch ihre Freien und Edelfreien (falls man die Termini hier aufgreifen will ${ }^{71}$ ) - eine natio auch in diesem Sinne? Aufzeichungen einer Lex liegen für sie nicht vor, doch allein darum das Gegenteil anzunehmen, schiene mir absurd. Kein Zusammenleben ist denkbar ohne gewisse, anerkannte Ordnungsvorstellungen, was "recht», was »unrecht" ist und auf welche Weise gegebenenfalls das zweite gesühnt werden kann, damit das Leben unbeschadet weiterzugehen vermag. Mit unserer Kentnis altslawischen Rechts ist es allgemein schlecht bestellt, doch die wenigen Indizien - kaum eine Hand voll - reichen aus, seine Existenz zu erhärten ${ }^{72}$. Solche aus dem Obermaingebiet sind dabei nicht beteiligt, doch dies darf getrost als Überlieferungszufall gewertet werden. Das karolingerzeitliche Personalitätsprinzip dürfte Möglichkeiten für die praktische Handhabung auch unter fränkischer Herrschaft offengelassen haben, nur daß auch sie sich dem Einblick entziehen. Das Würzburger Sondersendrecht zeigt ja die ganze Bevölkerung dieser Landschaften, slawisch oder nicht, fest in das damalige Herrschaftsgefüge eingebunden.

Schon deshalb unterlag sie auch einem Anspruch, der wie selbstverständlich an alle Reichsangehörigen ging: dem Auspruch, Christen zu sein, was immer die Zeit darunter verstand ${ }^{73}$. Die Art, wie sie damit umgingen - Slawen und sonstige Reichsuntertanen - war der Anlaß, aus dem dieses Sondersendrecht entstand. Sie verdient, intensiver unter die Lupe genommen zu werden.

${ }^{69}$ B. GUTTMANN, Die Germanisierung der Slawen in der Mark, in: Forschungen zur Brandenburgischen und Preußischen Geschichte 9 (1897), S. 457-468, passim; K. G. HUGELMANN, Die Rechtsstellung der Wenden im deutschen Mittelalter, in: Zschr.f.Rechtsgesch., Germ Abt. 58 (1938), S. 224-256, passim; R. SCHMIDT-WIEGAND, Die Wolfenbütteler Bilder-Handschrift des Sachsenspiegels (Wolfenbütteler Hefte 13), Berlin 1983, S. 42-47, passim. - R. DOVE, Beiträge zur Geschichte des deutschen Kirchenrechts I, in Zschr.f.Kirchenrecht 4 (1864), S. 35 f. m. Anm. 20, dazu DERS. im gleichen Bande (wie oben Anm. 26), S. 163 erörtert und belegt an einem Beispiel aus anderer Gegend die Möglichkeit »mächtiger Stammesabneigung" als Grundlage solcher Bestimmungen. Wie weit das karolingerzeitliche Personalitätsprinzip weltlichen Rechts zur Erklärung ausreicht, wäre zu prüfen.

${ }^{70}$ Hinweise z.B. bei DOVE, wie Anm. 69, erster Beitrag, S. 35-37.

${ }^{71}$ Beleg für slawische Freiheit aus dem fraglichen Gebiet noch im 12. Jh. bei E. HERMANN (wie Anm. 48), S. 1 ff.; ebd., S. 16-20, über Adelsstrukturen. Dazu noch J. SCHÜTZ, Ortsnamentypen und slawische Siedlungszeit in Nordostbayern, in: JFLF 28 (1968), bes. S. 313 f., 316, 318f; ENDRES (wie Anm. 48), S. 170; H. JAKOB, Zur Gentilaristokratie der Main-und Regnitzwenden, in: Arch.f.d.Gesch. Oberfrankens 62 (1982), S. 13-20.

${ }^{72}$ LIERMANN (wie Anm. 60), bes. S. 1-10, passim; JAKOB, S. 14. Anders E. HERRMANN 1968 (wie Anm. 27), S. 89-97, passim, demgegenüber aber E. MEYER, Geschichte des Altertums I/1: Elemente der Anthropologie, 6.Aufl. Darmstadt 1955, S. 36-49. - Spuren altslawischen Rechts sind karg, vgl. für den Südosten H. WOLFRAM, Salzburg - Bayern - Österreich, München 1995, S. 50 m. Anm. 217 f.; für das ostfälische Wendengebiet W. BARKHAUSEN, Die Gesetzgebung Wichmanns von Magdeburg, in: Deutsches Archiv 4 (1941), S. 49 ff. Beachtlich I. WIEHL, Die Rechtswörter in den Freisinger Denkmälern, in: Studia Slavistica (Marburger Abhandlungen zur Gesch.u.Kultur Osteuropas 21), Gießen 1981, S. 59-79. Zur Vorsicht gegenüber der verbreiteten Annahme einer alten gesamtslawischen Rechtsgemeinschaft mahnt F. GRAUS, Die Entwicklung Mitteleuropas im 8. Jh., in: Settimane di studi del Centro italiano di studi sull' alto medioevo 20 (1973), S. $476 \mathrm{f}$.

${ }^{73}$ Dazu merkwürdige Befunde bei KAHL (wie Anm. 3), S. 45-52. 


\section{Idolatria, idolothytum und paganismus im Übergangsfeld zwischen alter und neuer Religion}

Die nichtfränkischen nationes im weitgespannten Sprengel des spätkarolingischen Würzburg waren getauft (post perceptam baptismi gratiam). Sie waren damit verpflichtet, den Vorschriften ihrer Priester (divinis sacerdotumque suorum...praeceptis) zu folgen und überhaupt ihr Taufgelübde (iurata) einzuhalten. Der erste Akt der Christianisierung, die formale »Einkirchung « ${ }^{74}$, lag hinter ihnen: Die Kindertaufpflicht - das wird wenig beachtet - wurde bereits so selbstverständlich erfüllt, daß es nicht mehr notwendig erschien, sie, wie in anderen Texten, einzuschärfen ${ }^{75}$ - ihre Vernachlässigung erscheint nicht mehr in der relativ langen Liste frevelhaften Tuns und Lassens. Sie sind nicht wirklich bekehrt, zeigen Widerstand gegen die Anforderungen der Kirche, üben gar Kulthandlungen vorchristlicher, also »heidnischer « Tradition, doch ihr »Heidentum» ist nicht ungebrochen; es beschränkt sich auf ein innerkirchliches Nachwuchern älterer Bestände, stellt sich dar als ein Synkretismus, aus Elementen beider Religionen gemischt, kirchlich gesehen eine Form von Häresie ${ }^{76}$. Der nicht genau übersetzbare Ausdruck paganismus, der dieser mainslawischen Religionsform der Übergangszeit gelegentlich aus Stempel aufgedrück wird $^{77}$, darf uns nicht verwirren. Paganus ist nicht einfach $»$ Heide $«^{78}$.

Wir sollten uns auch bei dieser Gelegenheit gegenwärtig halten, daß ein derartiger Synkretismus in einer meist länger gestreckten Phase zwischen »Einkirchung « und innerlicher Annahme des neuen Glaubens unter mittelalterlichen Verhältnissen so gut wie unausweichlich war. Das hat zwei Gründe. Der eine liegt auf Seiten der missionierenden Kirche, die meist vorschnell auf den Vollzug der Taufe als Rechtsakt drängt und die eingehendere Belehrung, was dieser Schritt eigentlich bedeutet, auf spätere innerkirchliche Nacharbeit verschiebt, für die es doch jahrhundertelang durch die Weitmaschigkeit des Netzes von Seelsorgestationen und den vielfach mäßigen Bildungsstand des Klerus erheblich an Voraussetzungen fehlt ${ }^{79}$. Der zweite Grund liegt an einem prinzipiellen Strukturunterschied zwischen dem Christentum und den Gentilreligionen älterer Art, die auch das alte Europa bestimmten. Er wirkte besonders auf Seiten derer, die bekehrt werden sollten, der sog. »Missionsobjekte«. Das Christentum ist eine Universalreligion mit Absolutheitsanspruch, verdichtet im Ersten Gebot des Dekalogs, der sich an jeden einzelnen richtet ohne Rücksicht auf Herkunft und Abstammung. Es denkt in den Ka-

\footnotetext{
${ }^{74}$ Terminus nach F. BLANKE, Die Missionsmethode des Bischofs Christian von Preußen, bei H. Beumann (Hg.), Heidenmission und Kreuzzugsgedanke in der deutschen Ostpolitik des Mittelalters (Wege der Forschung 7), Darmstadt $1963=$ 1973, S. 347 (Wiederabdruck aus Altpreuß. Forschungen 4, 1927); vgl. H.-D. KAHL, Zur Problematik der mittelalterlichen Vorstellung von »Christianisierung«, bei Z. H. Nowak (Hg.), Die Rolle der Ritterorden in der Christianisierung und Kolonisierung des Ostseegebietes (Ordines militares I), Toruń 1983, S. 125-128, in Weiterführung der grundsätzlichen Ausführungen von BAETKE (wie Anm. 64); vgl. KAHL (wie Anm. 3), S. 42-50 u. weiter.

${ }^{75}$ Vgl. Capitulatio (wie Anm. 17), c. 19 (S. 69, 33 ff.); R. MEISSNER, Die norwegische Volkskirche nach den vier alten Christenrechten (Deutschrechtl. Archiv 2), Weimar 1941, S. $11 \mathrm{f}$.

${ }^{76}$ H.-D. KAHL, Compellere intrare. Die Wendenpolitik Bruns von Querfurt, bei Beumann (wie Anm. 74), S. 208 f. (Wiederabdruck aus: Zeitschr.f. Ostforschung 4, 1955, S. 185), und DERS. (wie Anm. 3), S. 52 f.

77 Unten bei Anm. 106-110.

${ }^{78}$ KAHL (wie Anm. 76), S. 204-208; vgl. DERS (wie Anm. 3), S. 52 f., dazu S. 26-29, 46 f., 58 u.ö. - Nicht zugänglich war S. ROSIK, Rudes in fide gentium populi. Fortwirken des Heidentums zur Zeit der Christianisierung der Slawen im Licht der deutschen narrativen Quellen des 11. u. 12. Jh., in: Quaestiones Medii Aevi Novae 7 (2002), S. 45-76. - Vgl. auch unten Anm. 110.

${ }^{79}$ KAHL (wie Anm. 3), s. 45-59.
} 
tegorien des »entweder - oder«. Die alten Gentilreligionen halten demgegenüber nichts für weniger selbstverständlich als universale Geltung gleichartiger Normen. Sie denken eher in einem »sowohl - als auch«, jederzeit bereit, neue Numina in ihr Pantheon aufzunehmen, wenn sie sich als mächtig und einflußreich auch für ihren Verband erweisen, doch nicht bereit, darum von den erprobten Göttern ihrer alten Tradition zu lassen. Daß der »deutsche Gott «, wie es von slawisch-gentilreligiöser Warte aus gelegentlich heißt ${ }^{80}$, allein herrschen will und daß mit den Teufeln, denen das Taufgelübde abschwört, auch eben diese altthergebrachten Lebenspartner gemeint sind, das will meist noch generationenlang nicht in gentilreligiös vorgeprägte Köpfe, und es verbindet sich mit der Furcht, die Unterlassung bisher gewohnter Verehrung könne Reaktionen zornigen Schadens von Seiten der sträflich Vernachlässigten auslösen ${ }^{81}$.

Es muß gesehen werden: Ein sendrechtlicher Text kann diese Situation nur unvollkommen beleuchten. Er ist nicht um ein Gesamtbild bemüht - er hebt Negativa hervor, die zu beseitigen sind; Aspekte der Volksfrömmigkeit, die die Urheber positiv werten, fallen für ihn nicht ins Gewicht. Ablehnung bestimmter Anforderungen an christliche Lebensführung und Widerstand gegen die Zumutung der Zehntleistung kann sich sehr wohl mit gelebten kirchlichen Frömmigkeitsformen verbinden, in ein und derselben Person wie auf verschiedene verteilt. Wir sollten die Zahl möglicher individueller Spielarten in derartiger Übergangszeit nicht unterschätzen. Doch an vorgefundenen christlichen Aspekten im Gesamtbild des herrschenden Synkretismus hatte ein Synodalbeschluß, der Ordnung zu schaffen suchte, nichts zu rügen. Für sie zeugt er allein mit dem Hinweis auf vollzogene Taufe und mit Negativbefunden wie der Nichtmehrberücksichtigung des Kindertaufzwangs; weitergehende Belege sind vom ihm nicht zu erwarten. Der Lichtkegel konzentriert sind ganz auf widerchristliche Befunde, gleich, ob uns damit Wesentliches entgeht.

Im Vordergrund stehen zunächst Widerstände gegen das, was die Kirche fordert. Sie müssen erheblich gewesen sein, denn die Gegenmittel, die eingesetzt werden sollen, sind von gesteigerter Drastik, mehr als in vielen vergleichbaren Fällen. Sie wecken die Frage, wie freiwillig wohl die Taufen der ersten Christengeneration im Lande waren - wieviel Auflehnung sie weckten, die sich bei nicht so ganz wenigen weitervererben konnte. Schon ALBERT HAUCK stellte fest: »Man kann nicht umhin, an einen Befehl des Königs zu denken, der die Annahme des Christentums gebot und dadurch mehr den Namen als die Religion des Landes änderte ${ }^{82}$; es drängt sich auf, daß die Umsiedelung widerspenstiger sächsischer Elemente nach Oberfranken, um ihre Starrnackigkeit zu brechen, ein Aufnahmegebiet voraussetzt, in dem die Kirche einigermaßen etabliert war. Doch für Einzelheiten fehlt uns jede Kenntnis. Was feststeht, sind die noch tief im 11. Jahrhundert fortwirkenden Widerstände ${ }^{83}$.

${ }^{80}$ Ebo, Vita Ottonis Babenbergensis Episcopi III.1 (ed. Jaffé - wie Anm. 48 - , S. 651): quante fortitudinis est Teutonicus deus, und weitere Stellen; dazu H.-D. KAHL, Slawen und Deutsche in der brandenburgischen Geschichte (Mitteldeutsche Forschungen 30/I-II) - Köln-Graz 1964, S. 78-80, vgl. auch DENS:, Heidnisches Wendentum und christliche Stammesfürsten, in: Arch. f. Kulturgeschichte 44 (1962), S. 93-95.

${ }^{81}$ Über gentilreligiöse Mentalität: KAHL 1962, S. 88-102; ausführlicher DERS. 1964, S. 76-102 (eher geschrieben, doch später ausgeliefert, daher mit unzulänglicher, in der jüngeren Arbeit berichtigter Terminologie). Erganzend DERS. (wie Anm. 17), S. 83-94; bes. 91 ff.

${ }^{82}$ A. HAUCK, Kirchengeschichte Deutschlands II, 8. Aufl. Berlin 1954, S. 354. - Bekannt ist Karls Weisung, undatiert bezeugt, im Slawenland an Main und Rednitz Kirchen zu bauen, vgl. MGH Form. imper. 40, S. 317 f.; von späteren Herrschern mehrfach wiederholt.

${ }^{83}$ S. oben Anm. 48. 
Hinzu kommen die klaren Hinweise auf »heidnisches« Wesen (more gentilium ${ }^{84}$ ), auf weiterbestehenden vorchristlichen Kult. Wie gezeigt, wird er mit zwei verschiedenen Ausdrücken charakterisiert: einem, der eindeutig slawisch, und einem, der ebenso eindeutig germanisch ist. Wie weit der zweite, der Hinweis auf Bestattungen bei den hougir, auch slawischen Brauch mitmeint, bleibt offen. Mit dem ersten kehren wir zum Ausganspunkt der Untersuchung zurück. Was erfahren wir aus Würzburgs Sondersendrecht über altslawischen Opferbrauch, ob die einheimische Mundart ihn nun trebo nannte oder, wie sonst, treba?

Zunächst: trebo ist wahrscheinlich das einzige Wort, genauer: die einzige Wortform aus dem Mainslawischen, die unabhängig von Namenüberlieferung auf uns gekommen ist. Schon das gibt ihr ein gewisses Gewicht. Zweitens ist es die einzige eindeutig slawische Kulthandlung, die für diesen Bereich ausdrücklich genannt wird. Dazu fällt auf, daß für die schon erwähnten Freisinger Denkmäler, die für frühes slawisches Christentum des Ostalpenraums sprechen, dasselbe gilt. Diese Textgruppe schließt an zweiter Stelle ein umfassendes Sündenbekenntnis ein. Dort erscheint unter aufgezählten Teufelswerken (dela Sotonina) an erster Stelle trebu tuorim "wir bringen (heidnische)

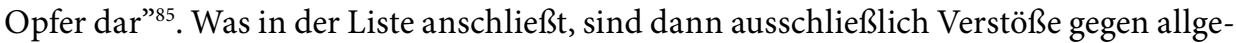
meine Gebote der Ethik: Verleumdung, Diebstahl, Totschlag, Fleischeslust, Meineid und Mißgunst. Die Sonderstellung der ersten Sünde im Rahmen des Ganzen ist deutlich. Andere Beichtformeln, etwa althochdeutsche, die für Phasen eines schon stärker gefestigten Christentums zeugen, setzen, soweit sie überhaupt Vergleichbares aufnehmen, an entsprechender Stelle "Unglauben" und "Zauberei« ein. Der Freisinger Text folgt nicht ihnen, sondern lehnt sich hier an eine Bibelstelle, an Gal. 5,20 an ${ }^{86}$ - treba vertritt dortiges idolorum servitus, ersetzt also einen allgemeinen Begriff durch eine konkrete Handlung. Beide, das Freisinger Denkmal und das Würzburger Sündenverzeichnis, stellen also treba/trebo als das wichtigste, zumindest auffälligste und am stärksten nachwirkende Kultgeschehen des vorchristlichen Slawentums heraus.

Dabei gibt der mainfränkische Text bemerkenswert mehr als der aus dem baierischen Missionsgebiet. Tvoriti bezeichnet ein einfaches »Darbringen«, »Zelebrieren«. Das läßt die Möglichkeit eines Brandopfers nach israelitischem Muster offen, bei dem das Opfertier gänzlich vernichtet wird. Qui idolothita quod trebo dicitur uel obtulerit uel manducauit - das fügt nicht nur eine Definition aus biblischem Sprachgebrauch hinzu, die klar auf ein »Opfermahl« hinweist ${ }^{87}$; es ergänzt auch die Opferhandlung ausdrücklich durch anschließendes »Essen«. Das ist ein Gewinn an Deutlichkeit. Trebo/treba entpuppt sich als eine Opferfeier, mit der sich ein kultisches Speisen verband, also ein Fest

\footnotetext{
${ }^{84}$ Dazu oben Anm. 45.

${ }^{85}$ Brižinski spomeniki. Znanstvenokritična izdaja (Slovenska akademija znanosti in umetnosti, Razred za filološke in literarne vede 39), Ljubljana 1993, S. 52, zu II, 20 (Herausgeber: I. Grdina), deutsche Übersetzung S. 113 (von K. D. Olof); vgl. O. KRONSTEINER, Die Freisinger Denkmäler. Lesart und Übersetzung, in: Die slawischen Sprachen 53 (1997), S. 10 f. - Nicht vorgelegen hat die weitere Neuedition von R.J. BRUNNER, Die Freisinger Denkmäler, in: Historische Sprachforschung 110 (1997), S. 292-307.

${ }^{86}$ O. KRONSTEINER, Waren in der Salzburger Kirchenprovinz schon vor Method Teile der Bibel ins Altslowenische übersetzt? In: Die slawischen Sprachen 53 (1997), S. 33 Nr 3.- Die Grundthese dieses Beitrages ist nicht weniger glaubhaft als die erwiesene Tatsache, daß im England Alfreds d.Gr. Entsprechendes auf Altenglisch geschah, nicht zu liturgischem Gebrauch, der der Vulgata vorbehalten blieb, aber zu Lehr- und Studienzwekken.

${ }^{87}$ Oben bei Anm. 25.
} 
feiernder Gemeinschaft, und es gab im frühen 10. Jahrhundert am Obermain Menschen, die es auch als Getaufte noch begingen, als nominelle Christen ${ }^{88}$.

Damit allerdings endet die Auskunft bereits. Schon wer die sakrale Handlung vollzog, bleibt offen - damit die Frage, ob es auch unter den Slawen dieser Gegend, wie anderweitig, einen besonderen Priesterstand gab und wie weit er die offizielle Christianisierung überlebte. Traten dann andere Würdenträger als heimliche Zelebranten ein? Gern wüßten wir auch, ob Feiern dieses Namens häufiger abgehalten wurden oder nur an wenigen hohen Festtagen, womöglich nur einem bestimmten, wie dies der Befund des Dravänopolabischen nahelegen könnte ${ }^{89}$. Idolothita ist Pluralform, trebo spiegelt einen Singular - das barbarische Latein der Quelle versäumt es, einen Ausgleich zu schaffen.

Weiter: Welchem Zweck sollte die Kulthandlung "nutzen ${ }^{90}$ ? Galt sie schlicht einer allgemein geschuldeten - »notwendigen ${ }^{91}$ - Verehrung, deren Unterlassung Schaden heraufbeschwören könnte? $\mathrm{Zu}$ den Möglichkeiten, die die Etymologie andeuten könnte, gehört die Funktion als Reinigungs- und Sühneopfer. Doch kommt sie in Betracht? ALEKSANDER BRÜCKNER hat auf den großen Abstand hingewiesen, den die slawische Religion zwischen Gottheiten und Menschen empfand, und darauf, daß höhere Mächte, wie sie sie sieht, nirgends erkennbar als Wächter über ethische Werte in Erscheinung treten; sie nahmen an Verhalten und Schicksal von Einzelpersonen offenbar keinerlei Anteil, ähnlich wie im vorchristlichen Germanentum ${ }^{92}$.

Das erwähnte Julfest des germanischen Nordens, um die Mittwinterzeit begangen wie das Tribe/Trewe im verchristlichten »Hannöverschen Wendland « ${ }^{93}$, brachte Opfer mit kultischem Mahl til árs ok friðar, »für ein Jahr (mit guten Erträgen) und guten Zusammenhalt (oder: gute Sicherheit) der feiernden Gemeinschaft«, wie die Kurzformel sich umschreiben läß $\mathrm{t}^{94}$. Im slawischen Bereich fehlt, soviel ich sehe, eine entsprechende Formel, aber ein ähnlicher Inhalt paßte gut zu einer Feier seiner Gentilreligion ${ }^{95}$. Hatte trebo/treba am Obermain eine entsprechende Funktion und damit zugleich hochpolitische Brisanz? Sorge um kommenden Erntesegen würde das beharrliche Festhalten an diesem Brauch besonders verständlich machen, doch die Quelle war an nichts interessiert als an der Widerchristlichkeit von Vorkommnissen und Bräuchen, wie man sie damals verstand.

Gern wüßten wir nicht zuletzt, an welche Gottheit oder Gottheiten die heilige Handlung sich zu richten hatte - ob überhaupt an eine Gottheit oder vielleicht nur an die Seelen Verstorbener im Totenkult ${ }^{96}$. Man hat zwar aus dem Text gefolgert, er deute mit seinen idolothita auf Kultbilder hin ${ }^{97}$. Träfe dies zu, so wäre wenigstens diese Frage geklärt, doch nicht einmal so viel ist sicherzustellen.

Unstreitig ist in dem definierenden Ausdruck idolum enthalten. Doch »Götzendienst « ist schon neutestamentlich nicht zwingend an Verehrung von Idolen gebunden;

${ }^{88}$ S. Anm. 73.

${ }^{89}$ Oben bei Anm. 5-9.

${ }_{90}$ Vgl. die Daten nach Anm. 1

91 Ebd.

92 BRÜCKNER (wie Anm. 2), S. 521; für Germanisches: B. REHFELDT, Todesstrafen und Bekehrungsgeschichte, S. 90-102; S. 39-45 ist slawisches Vergleichsmaterial verarbeitet, das gleiche Folgerungen nahelegt.

${ }^{93}$ Oben bei Anm. 5-9.

94 S. Anm. 6.

95 Gentilreligiöse Struktur: oben Anm. 80.

96 BRÜCKNER, S. 521.

${ }^{97}$ E. HERRMANN 1968 (wie Anm. 27), S. 96; ENDRES (wie Anm. 48), S. 174 u.a.m. 
entscheidend ist das Setzen von Nichtgöttlichem gegen den einen und einzigen Gott ${ }^{98}$. Gerade für die Slawen bezeugt einer unserer wichtigsten Gewährsleute, Helmold von Bosau, es sei ihnen »eine vielfältige Art von Götzendienst ( $y$ dolatriae modus) eigen... Die einen stellen phantastische Bildwerke in Tempeln zur Schau (simulacrorum ymaginarias formas), andere (Gottheiten) wohnen in Wäldern und Hainen... und werden nicht abgebildet (quibus nullae sunt effigies expressae) «, doch ihre Verehrung ist mit unter den Begriff $y$ dolatria gebracht ${ }^{99}$. Es gibt kein urslawisches Wort für das Kultbild, stattdessen eine bunte einzelsprachliche Palette; dergleichen ist also wohl sekundär unter Fremdeinflüssen zustandegekommen ${ }^{100}$, und es hat sich, wie Helmold zeigt, nicht allgemein durchgesetzt, so daß auch auf engem Raum Verschiedenes nebeneinanderstehen konnte - Analogieschlüsse sind selbst zwischen benachbarten Orten nicht ohne weiteres vertretbar. Was aber idolothytum angeht, so genügt die eine Definition, die ein vielbenutztes Bußbuch bringt, das auch noch von Burkhard von Worms bearbeitete ältere Poenitentiale ecclesiarum Germaniae, auch Corrector genannt. Er spricht unter diesem Begriff von »Opfergaben, die mancherots an den Gräbern Verstorbener dargebracht werden" - eine mögliche Stütze für trebo als Form von Totenkult, doch es geht weiter: »oder an Quellen, Bäumen, Steinen und Kreuzwegen", also bildlosen Objekten meist alter Naturverehrung; die Art der Erwähnung zeigt, daß man von diesen Gaben nichts essen darf, was wieder zu Kontext des trebo im Würzburger Sondersendrecht paßt ${ }^{101}$. Man sieht: ohne einen ausdrücklichen Quellenhinweis kann Bilderdienst nirgends vorausgesetzt werden, weder slawisch noch sonst. Für die Mainslawen aber fehlt diesbezüglich jede Information; die sog. "Bamberger Götzen", die man mit in diesen Zusammenhang zu ziehen suchte, sind fernzuhalten - vielleicht steppennomadischen, jedenfalls nicht slawischen Ursprungs ${ }^{102}$. Es gibt keinerlei Anhalt, weder archäologisch

${ }^{98}$ Eph. 5,5: omnis fornicator aut immundus aut avarus, quod est idolorum servitus, non habet hereditatem... Dei... Vgl. Col.3,5: avaritiam quae est simulacrorum servitus. - Liber Poenitentialis Theodori Archiepiscopi Cantuariensis 27,7 (Ancient Laws and Institutes of England II, 1840, S. 33): Non licet...ire ad auguria, atque angelos nominare, et congregationes facere quae interdicta noscuntur... huic occultae idolatriae serviens... dereliquit Dominum...et se idolatriae tradidit. - Gregor VII., Reg. IV, 24 (MGH Epp.sel. II, S. 338): qui apostolice sedi oboedire contemnit, scelus idolatrie incurrit. - Helmold (wie Anm. 99), c. 95 (S. 330, 25ff): Vernachlässigung des Gottesdienstes zugunsten eines marktmäßigen Geschäftsbetriebes als permaxima ydolatria. - Fulcher. Carnot., Hist. Hieros. I,28,2 (ed. H.Hagenmayer, Heidelberg 1913, S. 303): Saraceni legem suam idolatrie superstitioso ritu exercerent. Wie sich zeigt, sind die Ausführungen von Th. OHM, Die Stellung der Heiden zu Natur und Übernatur nach dem hl. Thomas von Aquin, Münster 1927, S. 167 über den Idolatriebegriff des behandelten Theologen weit zurückreichend verallgemeinerungsfähig, auch wenn die Vorstellung von Bilderdienst immer wieder vorwaltet. - Vgl. bereits J. GRIMM, Deutsche Mythologie, 4.Aufl. Leipzig 1875/78, Bd. I, S. 87; III, S. $40 \mathrm{f}$.

${ }^{99}$ Helmoldi presb. Bozoviens. Chronica Slavorum, c. 84 (ed. H. Stoob, Ausgewählte Quellen z. deutschen Gesch. d.Mittelalters XIX, Darmstadt 1963, S. 288,18 ff.)

${ }^{100}$ MOSZYŃSKI (wie Anm. 2, Ende), S. 110-112.

${ }^{101}$ Poenitentiale Ecclesiarum Germaniae, c. 94, nach H. J. SCHMITZ, Die Bußbücher und das kanonische Bußverfahren II, Düsseldorf 1898 = Graz 1958, S. 430, zitiert bei W. BOUDRIOT, Die altgermanische Religion in der amtlichen kirchlichen Literatur des Abendlandes vom 5. bis 11. Jh., Bonn 1928 = Darmstadt 1964, S. 27: Comedisti aliquid de idolothyto, id est de oblationibus, quae in quibusdam locis ad sepultura mortuorum fiunt, vel ad fontes aut ad arbores aut ad lapides aut ad bivia... Vgl. S. 19-21. BOUDRIOT stellt den Passus in die Tradition des Caesarius von Arles (†542) und seiner geistigen Nachfolger.

${ }^{102}$ H.-D. KAHL, Der Millstätter Domitian, Abklopfen einer problematischen Klosterüberlieferung (Vorträge u. Forschungen, Sonderband 46), Stuttgart 1999, S. 39 m. Anm. 111, dazu S. 41 f. u. 57-60 mitsamt dem Vergleichsmaterial bei L.P. SŁUPECKI, Slavonic pagan sanctuaries, Varsav 1994, S. 198-228, passim, bes. S. 198 - 201, neuerdings zu ergänzen durch den Fund bei KAHL, Domitian, S. 49 f. m. Abb. 7 (S. 111). 
noch aus schriftlichen Quellen, ob die Mainslawen irgend zu Bilderkult übergingen oder nicht, und auch das Würzburger Sondersendrecht trägt nichts bei, diese Lücke zu schließen.

So zeigt sich: Dieser Diözesanbeschluß bleibt in all seiner Kargheit das wichtigste Zeugnis zur Religionsgeschichte der Slawen dieser Gegend, als das JERZY NALEPA ihn in Anspruch nahm ${ }^{103}$, doch zu fast allem, was wir dazu erfahren wollen, bleibt er stumm - und eben damit ein charakteristicher Zeuge für die Überlieferungslage, die uns im dortigen Frühmittelalter empfängt, nicht nur für seine Slawen.

Allerdings kommt ihm noch eine andere Bedeutung zu: Er beleuchtet etwas von der Vorgeschichte der Bamberger Bistumsgründung, für die er in einen weitklaffenden Hiat eintritt. Das berührt vor allem das, was man das "Slawenmotiv« bei dieser Gründung genannt hat. Aus unterschiedlichem Erkenntnisinteresse wurde es immer wieder heruntergespielt, womöglich zum bloßen Vorwand Heinrichs II., mit dem er die seinen Plänen abgeneigten Mitglieder des Reichsepiskopats zu ködern versuchte ${ }^{104}$. Unter den Argumenten sei hervorgehoben, daß Thietmar von Merseburg, wohlunterrichteter Zeitgenosse, in seinem ausführlichen Bericht dieses Motiv übergeht. ${ }^{105}$

Die Formulierung, an die diese Kontroversen sich heften, stammt aus des Herrschers Kanzlei. Sie lautet: ut et paganismus Slavorum ibi destrueretur et Christiani nominis memoria perpetualiter inibi celebris haberetur - bemerkenswert zweigliedrig gebaut in alter theologischer Tradition. ${ }^{106}$ Heinrich war zunächst für den geistlischen Stand erzogen und jedenfalls kein schlechter Lateiner. Er hat diesen Finalsatz, wo nicht selbst entworfen, jedenfalls genau verstanden und gutgeheißen. Eine Alternative ist nicht vorstellbar.

Die Aussage wird meist im Sinn eines Missionsplans aufgefaßt, der sich auf außerkirchliches »Heidentum « richte, vor vollzogener Einkirchung ${ }^{107}$. Zugegeben: Sie läßt sich in diesem Sinn verstehen. Als Zeitgenosse hat dies Patriarch Johannes IV. von Aquileia gezeigt, als er den widerstrebenden Bischof Heinrich von Würzburg brieflich zu beschwichtigen suchte - die vermehrten Möglichkeiten zum Spenden der Taufe (per lavacrum regenerationis) eröffneten doch so viel zusätzliche Gnadenwirkung ${ }^{108}$. Der höchste Würdenträger der abendländischen Christenheit nach dem Papst war der entscheidenden Synode persönlich ferngeblieben. Vielleicht wollte er dem Herrscher dafür durch diesen Brief einen anderen Gefallen tun und mag sich in der Hoffnung gewiegt haben, wenn selbst er sich zur Sache melde, werde das Eindruck machen. Doch er saß weit vom Schuß, ohne jeden persönlichen Einblick in die Verhältisse vor Ort, besaß nur indirekte Informationen. Es ist nicht unwahrscheinlich, daß er den paganismus des Herrscherdiploms, der offensichtlich auch ein Moment der mündlichen Verhandlungen wiedergibt,

${ }^{103}$ S. Anm 35.

${ }^{104}$ Reiche Lit. bei Chr. LÜBKE, Regesten zur Geschichte der Slaven an Elbe und Oder III (983-1013), Berlin 1986, Nr. 411 (S.264), bes. die Arbeiten v. GUTTENBERGs; weiteres bei J. EHLERS, Magdeburg - Rom - Aachen - Bamberg, bei Schneidmüller-Weinfurter (wie Anm. 63), S. 65 f. Vgl. oben Anm. 48.

${ }^{105}$ Thietmar. Merseb. Chronicon VI, 30-32 (ed. W. Trillmich, Ausgewählte Quellen zur deutschen Geschichte des Mittelalters IX, Darmstadt 1957, S. 275-279). Thietmar war 1007 noch nicht Bischof, sondern nur Mitglied des Magdeburger Domkapitels und Propst seines Familienstifts Walbeck. Er könnte als Begleiter seines Erzbischofs an der Frankfurter Synode beteiligt gewesen sein, hebt dies jedoch nicht, wie sonst, hervor (vgl. VI, 60, S. 308, $11 \mathrm{ff}$.).

${ }^{106}$ D.H. II, 143 (MGH DD III, S. 170, 40 f.); dazu KAHL (wie Anm. 53), S. 158 ff.

${ }^{107}$ S. Anm. 74.

${ }^{108}$ Druck bei JAFFÉ (wie Anm. 48), S. 31; vgl. v. GUTTENBERG (wie ebd.), Nr. 74 (S. 38 f.), dazu 34 (S. 21). 
falsch verstanden hat. Das Sondersendrecht, das einmal aus der Würzburger Diözese hervorgegangen war, zeigt eindeutig, daß die slawische und sonstige Bevölkerung dieses Sprengels schon ein Jahrhundert zuvor post perceptam baptismi gratiam lebte, so sicher sie weiterhin widerschristliche Handlungen vornahm. Eine Einkirchung war dort längst nicht mehr zu leisten, sondern nur noch innerkirchliche Nacharbeit, und Bischof Heinrich mag die weitergehende Formulierung des Patriarchen als ebenso schweren wie ungerechtfertigten Vorwurf vernachlässigter Grundpflichen aufgefaßt haben, der das Gegenteil von dem bewirkte, was der Brief hatte bezwecken sollen.

Der paganismus König Heinrichs ist auf nichts anderes zu beziehen als auf Mißstände, wie sie für einen früheren Zeitpunkt derselben Region das Würzburger Sondersendrecht an erster Stelle seines Sündenkatalogs hervorhebt: Dinge wie trebo und vielleicht noch immer Bestattung bei hougir. Er meint kein außerkirchliches "Heidentum", sondern das, was Karolingerurkunden der Bonifatiuszeit als paganiae brandmarken, die der populus Dei - das Gottesvolk der Getauften - zu unterlassen hat ${ }^{109}$. Die Bamberger Synode von 1059, die noch immer von mehr oder weniger denselben Tatbeständen stand, schildert entsprechend die vorwiegend slawische Bevölkerung ohne Erwähnung anderer als ritibus gentilium dedita, während sie gleichzeitig eine alte Formel anwendet, die für Zwangsmaßnahmen gegen innerkirchliche Abweichler gilt ${ }^{110}$.

All das steht in einem einzigen Strang. Doch auch der zweite Teil des zitierten Auszugs aus Heinrichs Urkunde gewinnt erst von hier aus seinen vollen Sinn. Die neue Bistumsgründung soll, wie es merkwürdig gewunden heißt, das "Eingedenksein des Christennamens « fördern (Christiani nominis memoria). Das Würzburger Sondersendrecht hilft uns, zu verstehen, wieso: Wer getauft ist, trägt den Christennamen, die Bevölkerung um den Obermain also seit Generationen. Doch sie hielt ihn nicht in Ehren, wie das die Kirche verstand - sie befleckte ihn durch ständige Paganismen, und das kommt seinem Vergessen gleich. Das neue Bistum mit verdichteten Seelsorgemöglichkeiten hatte dies abzustellen.

Die religionsgeschichtliche Situation bei Errichtung der Bamberger Diözese wird also durch den König vollkommen zutreffend geschildert. Soll das wirklich nur Vorwand gewesen sein? Heinrich II. war als Kleriker von der Gorzer Reform berührt worden. Die Zustände im Bamberger Umfeld hatte er bei früheren Aufenthalten kennenlernen können. Solche Verhältnisse mit dem gewählten Mittel zu ändern, lag im Rahmen seiner königlichen Zuständigkeit, und in Oberfranken hatte er auch die Macht dazu, sehr anders als etwa gegenüber den Ljutizen, die der Staatsmann in gleichzeitig gegebener

${ }^{109}$ Sog. Concilium Germanicum, a. 742, c. 5 (MGH Conc. II/1, Nr. 1, S. 3, 28 ff. = MGH Cap. I. 10, S. 25, 31 ff.; lat.-dtsch. auch bei RAU, wie Anm. 65, S. 376-381); vgl. Karl d.Gr., sog. Capitulare primum (ca.a. 769), c. 6 (MGH Cap. I, S. 45, 17 ff. ); weiteres bei E. BLUM, Das staatl.u.kirchl. Recht des Frankenreichs in seiner Stellung zu Dämonen-, Zauber- u. Hexenwesen, Diss. Köln 1938, S. 35 f., bes. 36 Anm. 1. - Vgl. den Indiculus superstitionum et paganiarum (MGH Capit. I, 108, S. 222, auch bei Rau, ebd., S. 444-449, mit deutscher Übersetzung), kommentiert u.a. von H. GALLÉE, Altsächs. Sprachdenkmäler, Leiden 1894, S. 249-255, vgl. 245 f., und E. WADSTEIN, Kleinere altsächs. Sprachdenkmäler, Norden-Leipzig 1899, S. 142-144. Ungedruckt blieb leider H. HOMANN, Der Indiculus superstitionum et paganiarum und verwandte Denkmäler, Diss./ms. Göttingen 1965, wo S. 160-165 auch die einschlägigen Kapitularien umsichtig mitbehandelt sind.

${ }^{110}$ S. Anm. 48, bes. JAKOB. Beachte, daß die im Text anschließenden Ausführungen, die die Angabe: abhorrens a religione Christiana präzisieren, ausschließlich mit Anforderungen an die praktische Lebensführung befaßt sind, nicht mit »Irrglauben« u. dgl. Religio ist im Sinn der Beachtung dieser Vorschriften gemeint, nicht als »Religion« im modernen Verständnis. Synkretistiche Frömmigkeitsäußerungen im Sinn der Ausführungen oben bei Anm. 73-82 bleiben auch hier nicht ausgeschlossen. 
Situation nicht verärgern durfte. Selbstverständlich tut man gut, keinem Politiker alles zu glauben, was er verlautbart, statt auf geflissentlich Unausgesprochnes zu achten, wie das die Forschung in diesem Fall reichlich getan hat. Ich sehe jedoch nichts, was uns hindern müßte, diesem Herrscher das Motiv intensiverer kirchlicher Nacharbeit unter den Slawen am Obermain, das er, und nicht als einziges, ausdrücklich anbietet, als eins unter anderen abzunehmen. Wenn Thietmar es unterdrückt, will das wenig besagen: Er war in der entsprechenden Aufgabe unter den zahlreichen Slawen seiner eigenen Diözese ein offenbarer Versager und hat dies wohl auch selbst empfunden ${ }^{111}$; das auch noch indirekt zu beleuchten, indem er Verdienste auf gleichem Felde in so unmittelbarer Nachbarschaft zum eigenen Sprengel hervorhob, sollten wir ihm nicht zumuten. So bleibt allenfalls die Frage, ob König Heinrich in seiner Verlautbarung Akzente tendenziös verschoben hat.

War es Manipulation, daß er für die betroffene Region allein von Slawen und ihrem Synkretismus sprach? Stellte er damit stillschweigend eine verschwindende Minderheit hin, als repräsentiere sie die Gesamtbevökerung? Der Synodalbeschluß von 1059 mahnt auch hier zur Vorsicht. Er hält immer noch fest, das Gemeindevolk im Bamberger Bistumsbereich (plebs huius episcopii), das die aufgezählten Mängel aufweise, sei zu einem sehr großen Teil slawisch (um sein maxima parte Slavonica, das auch "größtenteils" oder »mehrheitlich slawisch« bedeuten könnte, möglichst vorsichtig wiederzugeben). Ein solcher Beschluß ist für den internen Gebrauch bestimmt. Er kann kaum Interesse haben, tatsächliche Gegebenheiten wider besserer Wissen aller Beteiligten zu verdrehen. Man wird anzunehmen haben, daß der Slawenteil im Lande damals eher über als unter 30\% lag, wobei die sprachliche Sonderstellung ihn auffälliger machte als die Angehörigen unterschiedlicher deutscher Mundarten, die sich leicht miteinander verständigen konnten. Dann wird jedoch ein Halbjahrhundert früher mindestens dasselbe gegolten haben. Mit anderen Worten: Der vom Würzburger Sondersendrecht festgehaltene Zustand, nach dem dort neben ceterae nationes einzig Slawen namentlich nennenswert schienen, traf weiterhin $\mathrm{zu}$, mochten auch Relationen sich durch Zuwanderung verschoben haben mochte nicht zuletzt auch die Zahl der Zweisprachigen mittlerweile zugenommen haben (besonders in Mischsiedlungen, deren anzunehmender slawischer Zweitname dann mit völliger Eindeutschung verlöschen mußte und sich damit, das Bild verzerrend, unserer Überlieferung entzieht).

Die Königsformulierung von 1007 hält auch insofern stand. Die neu verfügbar gemachte Quelle aber hilft, auch in dieser Beziehung den Ausgangspunkt klarzustellen, von dem her die Entwicklung über die Entscheidungen dieses Jahres hinweg dem Stand von 1059 zustrebte.

\section{Neue Fragen}

Ausgeschöpft ist das Würzburger Sondersendrecht auch damit nicht. Beispielsweise bietet es noch Daten zur Herrschafts- und Sozialverfassung seiner Entstehungszeit, die sonst verstreut zusammengesucht werden müssen, in seltener Konzentration. Doch hier ist Beschränkung auf slawische Religionsgeschichte geboten, aus der die Quelle den Synkretismus der Frühphase nach der ersten Christianisierung berührt. Wir hätten uns reicheren Ertrag gewünscht, doch mit leeren Händen entläßt der vielseitige Text uns

${ }^{111}$ Thietmars Quellenwert zur religiösen Situation seiner Diözese: KAHL, Domitian s. 44-47. 
keineswegs; ja er bleibt in dem wenigen, das er freigibt, immer wieder unersetzbar. So dürfte es gerechtfertigt sein, ihm im gleichen Rahmen auch einmal eine neue Edition zu gönnen ${ }^{112}$.

Trebo/treba als Wort ist uns über alledem aus dem Blick geraten. Der Satz von den idolothita, die diesen Namen tragen, konnte fest in der Überlieferung verankert werden. Damit ist jedoch das vermeintliche »Paderborner Kapitular" ausgehebelt, das bisher als ältestes Zeugnis für das slawische Opferwort galt; mit ihm die Datierung auf 785, so eindrucksvoll weit vor der methodianischen $\mathrm{Zeit}^{113}$. Was hat nun als erster Beleg für diesen Ausdruck an die Stelle zu treten?

Für die Freisinger Denkmäler steht nur fest, daß ihr Grundstock karolingerzeitlich sein muß. Für die Textfassungen, die uns vorliegen, und damit für Einzelstellen haben wir nichts als die paläographischen Befunde als Andeutung eines terminus ante quem. Sie weisen für die hier herangezogene Formel in die letzten Jahrzehnte vor der ersten Jahrtausendwende, vielleicht die Jahre um 977/981 ${ }^{114}$. Textänderungen zwischen Entstehung und Niederschrift sind nicht auszuschließen ${ }^{115}$. Das Würzburger Sondersendrecht liegt nur in Abschriften vor, die noch einige Jahrzehnte jünger sind, doch es reicht mit Sicherheit Jahrzehnte weiter zurück; mit nachträglicher Umredigierung ist nicht zu rechnen. Keinesfalls geht es in eine Phase zurück, die noch vor den Anfängen des altkirchenslawischen Schrifttums liegt. Der älteste Beleg für trebo/traba muß ein anderer sein.

Der fragliche Passus des Sündenregisters aus Freising fußt, wie gezeigt, offenbar auf einem übersetzten Bibeltext ${ }^{116}$. War er methodianisch oder älter - salzburgisch ${ }^{117}$ oder gar aquileisch ${ }^{118}$ ? Vor allem aber: stand in dieser Vorlage bereits treba oder eine genauere Entsprechung zum idolorum servitus (bzw. der $\varepsilon i \delta \omega \lambda o \lambda \alpha \tau \rho \varepsilon i \alpha)^{119}$ ? Ging ihr als ältester Wortbeleg für trebo/treba womöglich noch ein anderer voraus, der greifbar wäre?

Ein Bündel von Fragen und Unsicherheiten! Hier bleibt nichts, als es stehen zu lassen.

${ }^{112}$ Eine solche ist für den nächsten Band dieser Zeitschrift in Vorbereitung. Sie wird auch über Quellen- und Datierungsfragen mehr ausführen, als im vorliegenden Rahmen tunlich war. - Die Gelegenheit sein benutzt, nochmals auf inhaltliche Auswertungen hinzuweisen, die die vorliegenden Ausführungen ergänzen: bes. KOENIGER 1912 (wie Anm. 29), und E. HERRMANN 1968 (wie Anm. 27), S. 92-97. Eigene Stellungnahmen des Verfassers, deren Aspekte nicht sämtlich hier aufgegriffen werden konnten: Bausteine zur Grundlegung einer missionsgeschichtlichen Phänomenologie des Hochmittelalters, in: Miscellanea Historiae Ecclesiasticae. Congrès de Stockholm. Août 1960, Louvain 1961, S. 74 f.; Rezension zu Schwarz (wie Anm. 11), in: Jahrbuch f. Gesch. Mittel- u. Ostdeutschlands 11 /Erg. Bd. (1967), S. 61; Schwerin, Svarinshaug usw., bei K. Zernack (Hg.), Beiträge zur Stadt- und Regionalgeschichte Ost- und Nordeuropas, Gießen 1971, S. 80; natio (wie Anm. 28), S. 72-76; Die ersten Jahrhunderte (wie Anm. 3), S. 56 f.

${ }^{113}$ Oben bei Anm. 16-19.

${ }^{114}$ I. GRDINA, Paleografska in historična problematika, in: Brižinski spomeniki (wie Anm. 85), S. 17, deutsche Zusammenfassung S. $183 \mathrm{f}$.

${ }^{115}$ K. D. OLOF, Zu den Katalogen in den Freisinger Denkmälern, in: Zbornik Brižinski spomeniki (Slovenska akademija znanosti in umetnosti, Razred za filološke in literarne vede 45), Ljubljana 1996, S. 92: »Wir haben also davon auszugehen, daß wir es im textlichen Bereich einerseits mit erheblichen Unterschieden in Erhaltung und Zuverlässigkeit, andererseits mit gezielten textgestalterischen Eingriffen zu tun haben«; folgt Ausführung am Beispiel der Interpolation von Laurentius-Invokation in FD III. Vgl. bes. noch S. 94.

${ }^{116}$ Oben bei Anm. 86.

${ }^{117}$ S. Anm. 80.

${ }^{118}$ Vgl. Ch. HANNICK, Die Freisinger Denkmäler innerhalb der Entwicklung des slavischen kirchlichen Wortschatzes, in: Zbornik (wie Anm. 115), S. 239-243, sowie DENS., Die älteste slavische Kirchenterminologie, bei R. Bratož (Hg.), Slovenija in sosednje dežele med antiko in karolinško dobo II, Ljubljana 2000, S. 801-807.

${ }^{119}$ Oben bei Anm. 86. 


\section{Ugaslo slovanstvo ob gorenji Maini in njegovo predkrščansko žrtvovanje (trebo) v luči domnevno würzburškega sinodalnega sklepa iz 10. stoletja}

\section{Hans-Dietrich Kahl}

Staroslovanski izraz trěba “žrtev” je komajda prestal pokristjanjevanje. Dozdevno najstarejše pričevanje iz leta 785 se kaže kot würzburški sinodalni sklep iz 10. stoletja. Govori o drakonskih ukrepih proti odpadnikom od cerkvenih pravil, ki pa so čudno omejeni na Nefranke. Slovanski in germanski cesarski podložniki se pojavljajo na isti ravni, tudi Slovani kot lastna pravna skupnost. Njihova religija je sinkretistična; stopnja njihove kristjanizacije ostaja neosvetljena. Vidni postajajo močni odpori cerkveni disciplini. Obredna pojedina trebo (sic) predstavlja enega od prepovedanih povratkov k "poganstvu". Kontekst daje priložnost za analizo jezikovne uporabe besed idolatria, idolothytum in paganismus ter za novo osvetlitev predzgodovine ustanovitve škofije Bamberg. 